\title{
A cardiac mitochondrial cAMP signaling pathway regulates calcium accumulation, permeability transition and cell death
}

\author{
Z Wang ${ }^{1}$, D Liu ${ }^{1}$, A Varin ${ }^{1}$, V Nicolas ${ }^{2}$, D Courilleau ${ }^{2}$, P Mateo ${ }^{1}$, C Caubere ${ }^{3}$, P Rouet ${ }^{3}$, A-M Gomez ${ }^{1}$, G Vandecasteele ${ }^{1}$, R Fischmeister ${ }^{1,2}$ \\ and $C$ Brenner*,1,2
}

\begin{abstract}
Although cardiac cytosolic cyclic $3^{\prime}, 5^{\prime}$-adenosine monophosphate (cAMP) regulates multiple processes, such as beating, contractility, metabolism and apoptosis, little is known yet on the role of this second messenger within cardiac mitochondria. Using cellular and subcellular approaches, we demonstrate here the local expression of several actors of cAMP signaling within cardiac mitochondria, namely a truncated form of soluble $\mathrm{AC}\left(\mathrm{SAC} \mathrm{C}_{t}\right)$ and the exchange protein directly activated by cAMP 1 (Epac1), and show a protective role for $\mathrm{SAC}_{\mathrm{t}}$ against cell death, apoptosis as well as necrosis in primary cardiomyocytes. Upon stimulation with bicarbonate $\left(\mathrm{HCO}_{3}^{-}\right)$and $\mathrm{Ca}^{2+}, \mathrm{SAC}_{\mathrm{t}}$ produces $\mathrm{CAMP}$, which in turn stimulates oxygen consumption, increases the mitochondrial membrane potential $(\Delta \Psi \mathrm{m})$ and ATP production. CAMP is rate limiting for matrix $\mathrm{Ca}^{2+}$ entry via Epac1 and the mitochondrial calcium uniporter and, as a consequence, prevents mitochondrial permeability transition (MPT). The mitochondrial cAMP effects involve neither protein kinase A, Epac2 nor the mitochondrial $\mathrm{Na}^{+} / \mathrm{Ca}^{2+}$ exchanger. In addition, in mitochondria isolated from failing rat hearts, stimulation of the mitochondrial CAMP pathway by $\mathrm{HCO}_{3}^{-}$rescued the sensitization of mitochondria to $\mathrm{Ca}^{2+}$-induced MPT. Thus, our study identifies a link between mitochondrial cAMP, mitochondrial metabolism and cell death in the heart, which is independent of cytosolic cAMP signaling. Our results might have implications for therapeutic prevention of cell death in cardiac pathologies.
\end{abstract}

Cell Death and Disease (2016) 7, e2198; doi:10.1038/cddis.2016.106; published online 21 April 2016

Mitochondria are involved in cell life and fate decision through their multiple biological functions in energetic metabolism, reactive oxygen species (ROS) detoxification and cell death. ${ }^{1-3}$ These functions are crucially regulated to provide sufficient energy for cell functions, maintain mitochondrial membrane integrity and avoid excessive cell death. ${ }^{4,5}$ Moreover, mitochondria may participate in $\mathrm{Ca}^{2+}$ homeostasis via matrix $\mathrm{Ca}^{2+}$ accumulation through the mitochondrial $\mathrm{Ca}^{2+}$ uniporter (MCU), $\mathrm{Ca}^{2+}$ release into the cytosol and propagation to other mitochondria, notably in excitable cells. ${ }^{6-8}$ In cardiomyocytes, intracellular $\mathrm{Ca}^{2+}$ movements are crucial for proper myofibril contraction and relaxation and energetic metabolism. Moreover, recent studies in cardiomyocytespecific mutant mouse lacking the MCU showed a link between mitochondrial $\mathrm{Ca}^{2+}$ uptake and energetic supply in relation with cardiac workload during acute stress. ${ }^{9,10}$ In contrast, excessive mitochondrial $\mathrm{Ca}^{2+}$ accumulation, ROS production and adenine nucleotide depletion result in the sudden opening of a megachannel, namely the permeability transition pore complex. The prolonged opening of this unspecific pore leads to the mitochondrial permeability transition (MPT), cell death, inflammation and irreversible tissue damage. ${ }^{11,12}$ MPT can be a critical event in severe cardiac diseases such as ischemia-reperfusion injury and heart failure (HF) as well a radiation-induced cardiotoxicity. ${ }^{11,13,14}$ Hence, MPT inhibition by cyclosporin A (CsA) has been shown to limit cardiac damages and improve cell survival. Inhibition of MPT has thus become an attractive therapeutic strategy in cardioprotection. ${ }^{15}$

Cyclic 3',5'-adenosine monophosphate (cAMP) is a major second messenger in many organs, particularly in the heart, where it regulates diverse physiological processes such as $\mathrm{Ca}^{2+}$ homeostasis, beating frequency and myocardial contractility as well as cell death. ${ }^{16}$ In the working myocardium, cAMP can activate protein kinase A (PKA) and/or the exchange protein directly activated by cAMP (Epac) to mediate diverse biological effects, including cardiac remodeling and hypertrophy. ${ }^{17-22}$ In addition to tmACs, cAMP can also be generated by soluble adenylyl cyclase (SAC), which is not regulated by heterotrimeric $\mathrm{G}$ proteins or forskolin (FSK), but can be activated by bicarbonate $\left(\mathrm{HCO}_{3}^{-}\right)$and $\mathrm{Ca}^{2+} \cdot{ }^{16,23,24} \mathrm{SAC}$ was found inside mitochondria in the brain and liver and in certain mammalian cell types. ${ }^{25-29}$ In the liver and brain, in response to $\mathrm{HCO}_{3}^{-}$and/or $\mathrm{Ca}^{2+}$, mitochondrial cAMP

\footnotetext{
${ }^{1}$ INSERM UMR-S 1180, Faculté de Pharmacie, Université Paris-Sud, Université Paris-Saclay, Châtenay-Malabry, France; ${ }^{2}$ UMS-IPSIT, Université Paris-Sud, Université Paris-Saclay, Châtenay-Malabry, France and ${ }^{3}$ INSERM I2MC, UMR 1048, Université Paul Sabatier, Toulouse, France

${ }^{*}$ Corresponding author: C Brenner, INSERM UMR-S 1180, Faculté de Pharmacie, Université Paris-Sud, Université Paris-Saclay, 5 Rue J-B Clément, Châtenay-Malabry Cedex 92296, France. Tel: (+33) 6609932 77; Fax: (+33) 14683 54 75; E-mail: catherine.brenner-jan@u-psud.fr

Abbreviations: 2HE, 2-hydroxyestradiol; AC, adenylyl cyclase; ANT, adenine nucleotide translocase; CCCP, carbonyl cyanide m-chlorophenyl hydrazone; CsA, cyclosporine A; $\triangle \Psi \mathrm{m}$, mitochondrial membrane potential; Epac, exchange protein directly activated by $\mathrm{CAMP} \mathrm{HCO}_{3}^{-}$, bicarbonate; $\mathrm{HF}$, heart failure; IM, inner membrane; $\mathrm{MCU}$, mitochondrial calcium uniporter; $\mathrm{mNCX}$, mitochondrial $\mathrm{Na}^{+} / \mathrm{Ca}^{2+}$ exchanger; MPT, mitochondrial permeability transition; OM, outer membrane; PKA, protein kinase $A ; R O S$, reactive oxygen species; $s A C$, soluble adenylyl cyclase; $s \mathrm{SC}_{f \mid}$, full-length soluble adenylyl cyclase; $s \mathrm{C}_{t}$, truncated soluble adenylyl cyclase Received 13.1.16; revised 17.3.16; accepted 21.3.16; Edited by G Raschellà
} 
stimulates oxidative phosphorylation and ATP production. ${ }^{30}$ In coronary endothelial cells, $\mathrm{HCO}_{3}^{-}$indirectly modulates the cell fate through apoptosis. ${ }^{31,32}$ As a result, this pathway serves as a mechanism for metabolic adaptation to mitochondrial dysfunction and could be a potential novel target to treat genetic mitochondrial diseases. ${ }^{33}$ Altogether, these findings suggest that mitochondrial SAC functions as a metabolic sensor to stimulate mitochondrial biological functions. If proven in primary cardiomyocytes, this intramitochondrial cAMP pathway might have clinical implication in $\mathrm{HF}$ as patients diagnosed with HF have markedly impaired mitochondrial metabolism and CAMP signaling, both contributing to cardiomyocyte dysfunction. ${ }^{16,34}$

Intrigued by these previous findings, we tested the existence of a cAMP mitochondrial pathway in differentiated adult and neonatal cardiomyocytes and observed that activation of this pathway prevents various cell deaths. Our results also show that cardiac mitochondria isolated from adult rat hearts contain a truncated form of $\mathrm{SAC}\left(\mathrm{SAC}_{\mathrm{t}}\right)$ as a source of cAMP as well as Epac1. A role of this local pathway is to control mitochondrial $\mathrm{Ca}^{2+}$ entry through the $\mathrm{MCU}$ and to prevent the deleterious consequences of mitochondrial $\mathrm{Ca}^{2+}$ overload such as dissipation of mitochondrial membrane potential $(\Delta \Psi \mathrm{m})$ and induction of MPT. Interestingly, this mitochondrial $\mathrm{SAC}_{\mathrm{t}}$-Epac1-MCU pathway remains functional in a rat model of HF induced by aortic stenosis and its activation prevents MPT.

\section{Results}

Mitochondrial cAMP prevents cardiac cell death, apoptosis as well as necrosis. To evaluate the capacity of SAC and CAMP to regulate the cardiomyocyte cell fate, we infected primary neonatal cardiomyocytes with two adenoviruses to overexpress the full-length $\mathrm{SAC}\left(\mathrm{SAC}_{\mathrm{fl}}\right)$ and the $\mathrm{sAC}_{\mathrm{t}}$, respectively, $24 \mathrm{~h}$ before cell death induction by three different cell death inducers, that is, camptothecin, $\mathrm{H}_{2} \mathrm{O}_{2}$ and TNF-a+actinomycin D. We showed that the stimulation of endogenous SAC with $\mathrm{HCO}_{3}^{-}$as well as overexpression of $\mathrm{SAC}_{\mathrm{t}}$ prevented the various cell death modalities, apoptosis as well as necrosis measured by annexin/7-AAD labeling (Figures 1a and b). In contrast, inhibition of SAC with 2-hydroxyestradiol (2HE), a sAC inhibitor, ${ }^{29}$ aggravated significantly cell deaths (Figure 1a). We observed also that cAMP protects from nuclei alterations measured by counting Hoechst-stained nuclei exhibiting morphologic and biochemical alterations, that is, pycnosis and karryorrhexis (Figures 1c-f).

\footnotetext{
Mitochondrial sAC produces locally cAMP and regulates $\Delta \boldsymbol{\Psi}_{\mathrm{m}}$ upon calcium overload. As mitochondria may be impermeant to cytosolic $\mathrm{CAMP}^{35}$ we constructed an adenovirus encoding a cAMP-sensitive fluorescence resonance energy transfer (FRET) sensor (Epac- $\left.\mathrm{S}^{\mathrm{H} 187}\right)^{36}$ fused with a $4 \mathrm{mt}$ sequence and infected rat neonatal cardiomyocytes with this sensor, $4 \mathrm{mt}-E$ pac- $\mathrm{S}^{\mathrm{H} 187}$. The localization of $4 \mathrm{mt}-\mathrm{Epac}-$ $\mathrm{S}^{\mathrm{H} 187}$ in mitochondria was shown by colocalization of its green fluorescence with mitotracker red fluorescence (Pearson's coefficient: $0.92 \pm 0.02, n=6$ ) (Figure 2a). Following
}

infection with $4 \mathrm{mt}-\mathrm{Epac}-\mathrm{S}^{\mathrm{H} 187}$, we sequentially treated the cells with $\mathrm{HCO}_{3}^{-}$to activate $\mathrm{SAC}$, FSK to activate tmAC and 8-CPT-2'-OMe-cAMP-AM (8CPT-cAMP AM), a permeant cAMP analog, to directly activate the sensor (Figure $2 b$ ). Addition of $\mathrm{HCO}_{3}^{-}$induced an increase in cAMP measured by $4 \mathrm{mt}-\mathrm{Epac}^{\mathrm{H}} \mathrm{S}^{\mathrm{H} 187}$ (Figure $2 \mathrm{~b}$ ), which was virtually absent when the cells were infected with the cytoplasmic cAMP sensor Epac-S ${ }^{\mathrm{H} 187}$ (Figure 2c). On the contrary, FSK induced a large response of cAMP measured with the cytoplasmic sensor (Figure 2c) and a smaller response of cAMP measured with the mitochondrial sensor (Figure $2 \mathrm{~b}$ ). These results are compatible with $\mathrm{HCO}_{3}^{-}$-activating $\mathrm{SAC}$ in mitochondria and FSK increasing CAMP in the cytoplasm by activating tmAC. The small response to FSK observed with $4 \mathrm{mt}-E$ pac- $\mathrm{S}^{\mathrm{H} 187}$ might be due to incomplete targeting of the probe to mitochondria. Of note, $4 \mathrm{mt}-\mathrm{Epac}-\mathrm{S}^{\mathrm{H} 187}$ has a much higher dynamic range than previously published sensors such as mito-EpacH90, ${ }^{35}$ so that even a small expression of the probe in the cytosol would lead to a detectable signal. Alternatively, the small response to FSK measured with $4 \mathrm{mt}-E$ pac-S ${ }^{\mathrm{H} 187}$ might be due to $\mathrm{Ca}^{2+}$ stimulation of $\mathrm{SAC}$ in the matrix upon FSK stimulation as suggested previously, ${ }^{29}$ or to a small permeability of the mitochondrial inner membrane (IM) to cAMP. Interestingly, 2HE totally prevented the mitochondrial cAMP increase elicited by $\mathrm{HCO}_{3}^{-}$(Figure $2 \mathrm{~d}$ ). This confirms the involvement of a mitochondrial SAC as a source of CAMP in cardiomyocytes.

To address the role of SAC in the regulation of mitochondrial function, cardiomyocytes were transfected with siRNA control and siRNA against SAC for $48 \mathrm{~h}$. Next, they were loaded with the fluorescent $\Delta \Psi \mathrm{m}$ indicator, TMRM, permeabilized and treated with $\mathrm{Ca}^{2+}$. The decrease in the level of SAC did not induce any changes of the mitochondrial network (Figures $2 \mathrm{e}$ and f). However, the measure of the TMRM fluorescence ratio showed that silencing of SAC markedly aggravated the loss of $\Delta \Psi \mathrm{m}$ induced by $\mathrm{Ca}^{2+}$, suggesting a role of cAMP in $\Delta \Psi_{\mathrm{m}}$ control in stress conditions.

CAMP is produced by SACt in isolated mitochondria. Mitochondria were isolated from rat heart ventricles by differential centrifugation and extensive washes. ${ }^{37}$ First, we analyzed their morphology by transmission electron microscopy (Figure 3a) and their purity by western blotting (Figure 3b). As expected, mitochondria appeared roundshaped (mean diameter, $0.8 \mu \mathrm{m}$ ) and presented numerous cristae, compatible with a high respiratory capacity. In comparison with rat ventricles homogenate $(H)$, isolated mitochondria $(\mathrm{M})$ were enriched in the adenine nucleotide translocase (ANT), an IM protein and almost not contaminated by cytosolic proteins such as GAPDH, myofibrillar proteins such as troponin I (Tnl) and sarcoplasmic reticulumassociated proteins such as phospholamban (PLB) (Figure 3b). Using specific monoclonal antibodies, we detected the $\mathrm{sAC}_{\mathrm{t}}(48 \mathrm{kDa})$ and the $\mathrm{sAC}_{\mathrm{fl}}(187 \mathrm{kDa})$ in $\mathrm{H}$ fraction, whereas only the short form, which is the active form, ${ }^{38}$ was found in the mitochondria preparation (Figure 3b). Next, we measured cAMP production in freshly isolated mitochondria. We observed that $\mathrm{HCO}_{3}^{-}$and also, to a lesser extent, $\mathrm{Ca}^{2+}$-stimulated cAMP production in a dosedependent manner and potentiated the response to ADP 

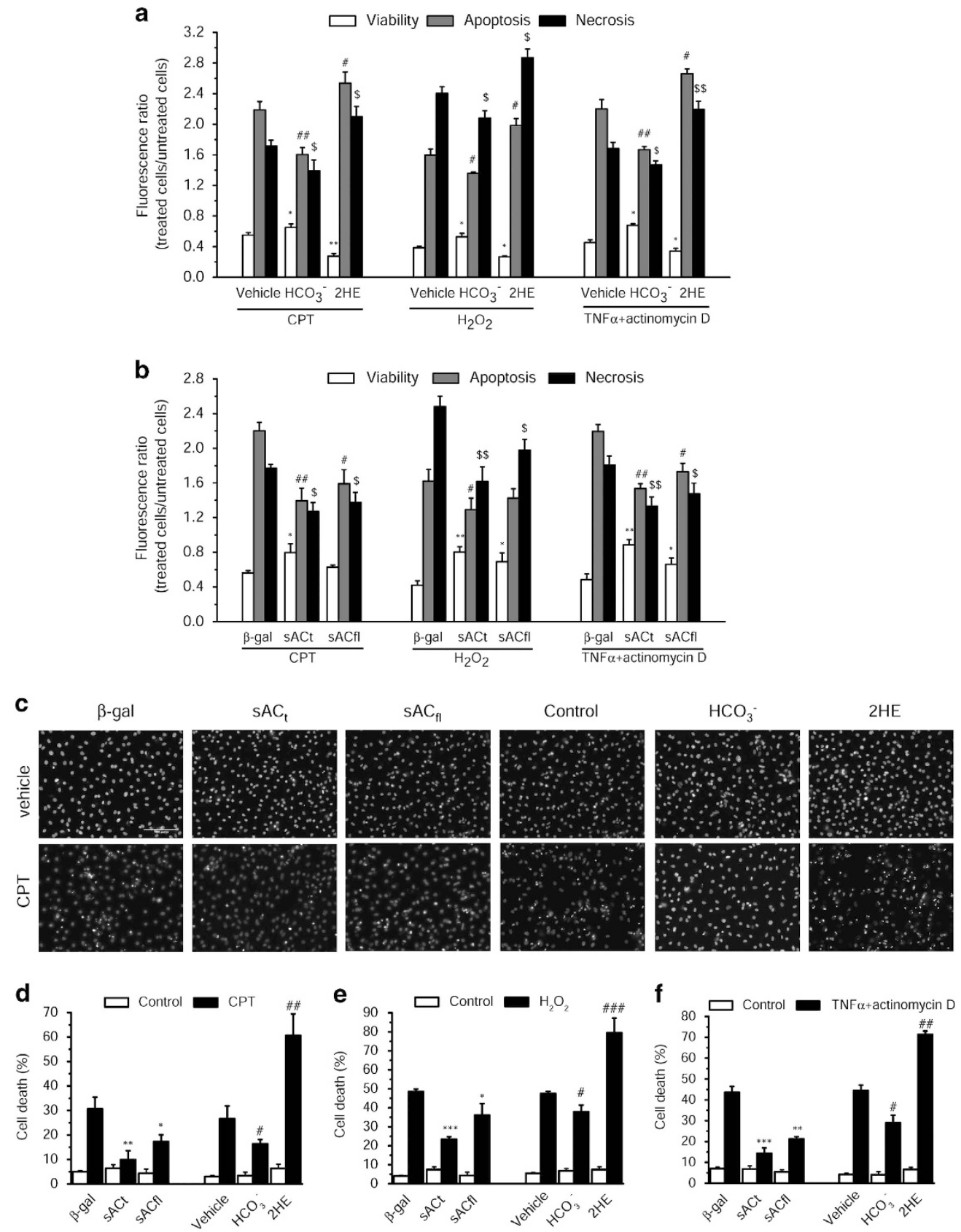

Figure 1 Mitochondrial cAMP protects cell death induced by camptothecin (CPT), hydrogen peroxide $\left(\mathrm{H}_{2} \mathrm{O}_{2}\right)$ and tumor necrosis factor- $\alpha$ (TNF $\alpha$ ) in neonatal cardiomyocytes. (a) Cells were treated with vehicle, $15 \mathrm{mM} \mathrm{HCO}_{3}^{-}$and $25 \mu \mathrm{M} 2 \mathrm{HE}$ in the presence of $10 \mu \mathrm{M} \mathrm{CPT}$ for $48 \mathrm{~h}$ or $300 \mu \mathrm{M} \mathrm{H}_{2} \mathrm{O}_{2}$ for $24 \mathrm{~h}$ or $10 \mathrm{ng} / \mathrm{ml} \mathrm{TNF} \alpha / 0.1 \mu \mathrm{g} / \mathrm{ml}$ actinomycin $\mathrm{D}$ for $24 \mathrm{~h}$. (b) Cells were infected by adenoviruses encoding $\beta$-galactosidase ( $\beta$-gal), sAC $\mathrm{C}_{\mathrm{t}}$ and sAC for $24 \mathrm{~h}$ and then treated with $10 \mu \mathrm{M} C P T$ for $48 \mathrm{~h}$ or $300 \mu \mathrm{M} \mathrm{H}_{2} \mathrm{O}_{2}$ for $24 \mathrm{~h}$ or $10 \mathrm{ng} / \mathrm{ml} \mathrm{TNF} \alpha / 0.1 \mu \mathrm{g} / \mathrm{ml}$ actinomycin $\mathrm{D}$ for $24 \mathrm{~h}$. ${ }^{*} P<0.05,{ }^{* \star} P<0.01$ versus vehicle or $\beta$-gal viability; ${ }^{\#} P<0.05$, ${ }^{\# \#} P<0.01$ versus vehicle or $\beta$-gal

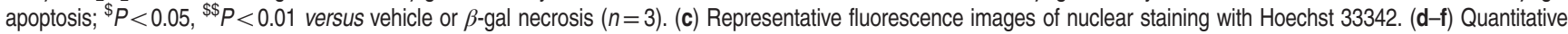
analysis of cell death rate. Cells were infected with adenoviruses encoding $\beta$-gal, $\mathrm{sAC}_{\mathrm{t}}$ and $\mathrm{sAC}_{\mathrm{fl}}$ for $24 \mathrm{~h}$ and then treated with $\mathrm{CPT}(10 \mu \mathrm{M})$ for $48 \mathrm{~h}, \mathrm{H}_{2} \mathrm{O}_{2}(300 \mu \mathrm{M})$ or TNF $\alpha$ /actinomycin D (10 ng/ml, $0.1 \mu \mathrm{g} / \mathrm{ml})$ for $24 \mathrm{~h}$, or cells were treated with vehicle, $15 \mathrm{mM} \mathrm{HCO}_{3}^{-}$and $25 \mu \mathrm{M} 2 \mathrm{HE}$ in the presence of CPT $(10 \mu \mathrm{M})$ for $48 \mathrm{~h}, \mathrm{H}_{2} \mathrm{O}_{2}(300 \mu \mathrm{M})$ or TNF $\alpha /$ actinomycin D (10 ng/ml, $0.1 \mu \mathrm{g} / \mathrm{ml})$ for $24 \mathrm{~h} .{ }^{*} P<0.05,{ }^{* \star} P<0.01,{ }^{* \star \star} P<0.001$ versus $\beta$-gal; ${ }^{\#} P<0.05,{ }^{\# \#} P<0.01,{ }^{\# \#} P<0.001$ versus vehicle ( $n=3$ )

(Figure 3c). Although a small stimulatory effect of $\mathrm{Ca}^{2+}$ on cAMP production was observed at $0.1 \mu \mathrm{M}$, when increasing the concentration to $10 \mu \mathrm{M}$, mitochondria lost their membrane potential (not shown), lowering markedly cAMP production (Figure $3 \mathrm{c}$ ). $\mathrm{Ca}^{2+}$ effects were abolished in the presence of RU360, confirming that the effect on cAMP levels is due to a specific uptake of $\mathrm{Ca}^{2+}$ within the matrix. Similarly, when mitochondria were depolarized by the protonophore carbonyl cyanide $m$-chlorophenyl hydrazone (CCCP), no cAMP production was detected even in the presence of $\mathrm{HCO}_{3}^{-}$ (Figure 3d). Moreover, 2HE reduced basal and fully blocked $\mathrm{HCO}_{3}^{-}$-stimulated cAMP production (Figure 3d). As a control, 
a
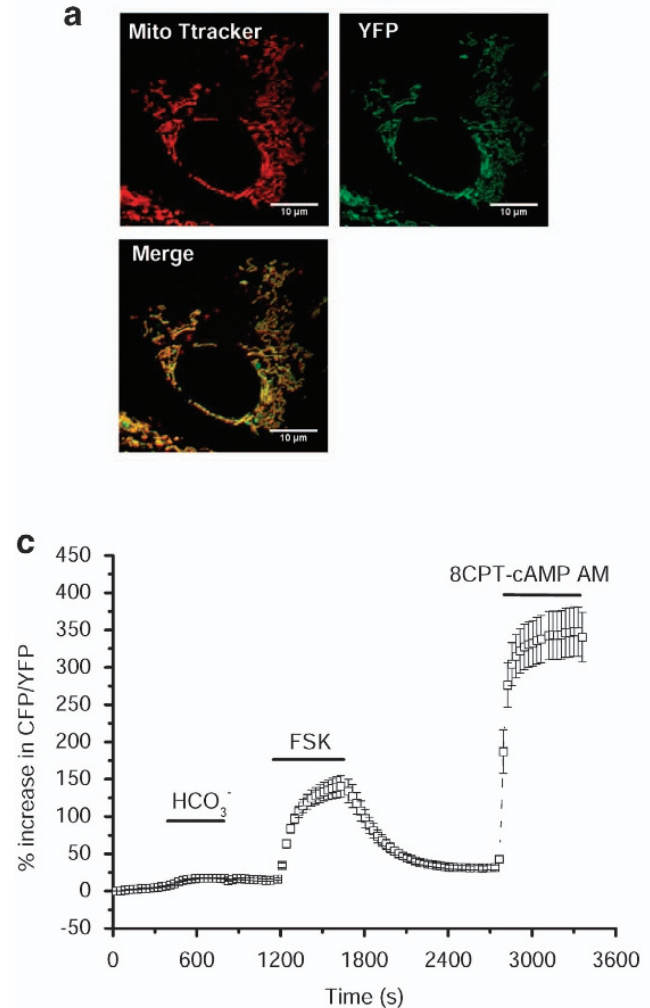

e

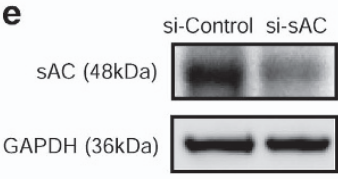

f
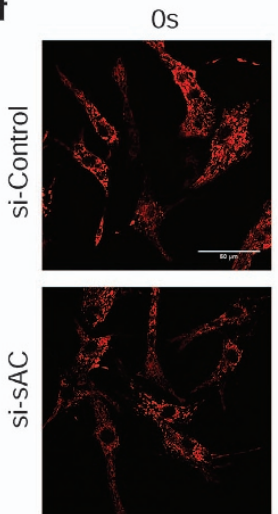
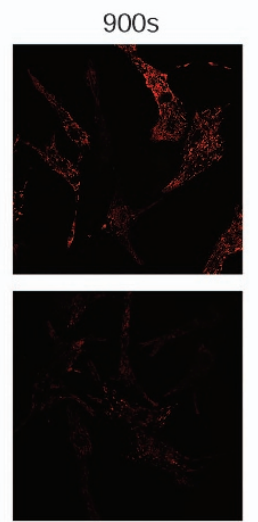
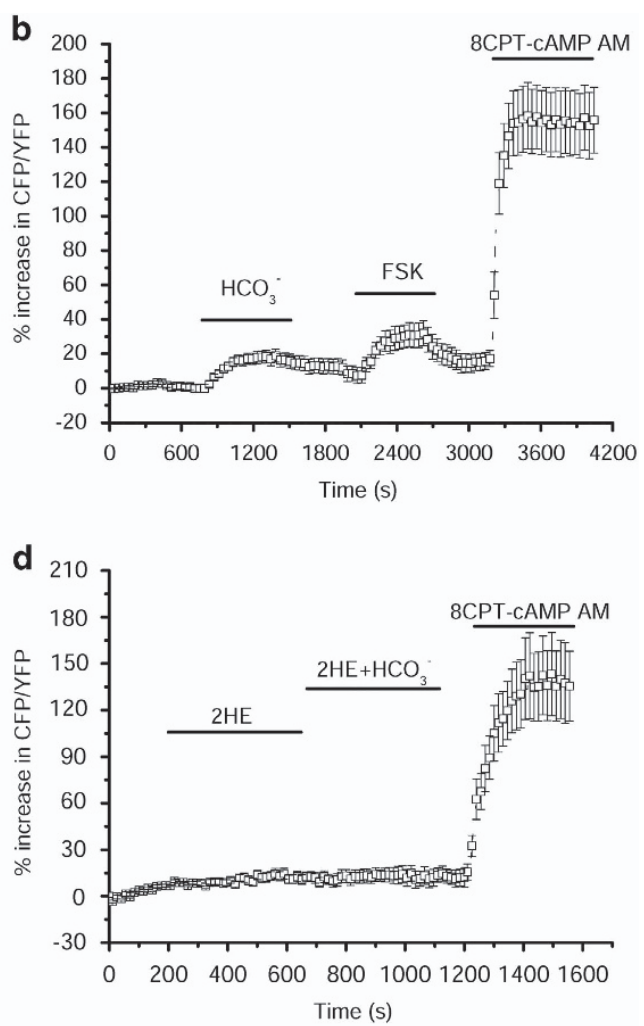

g

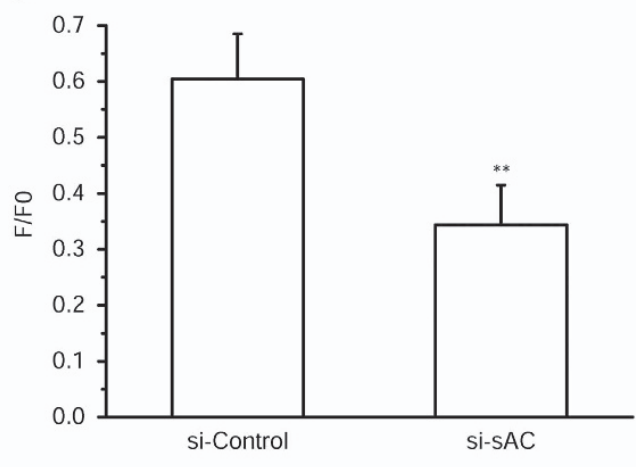

Figure 2 Mitochondrial sACt produces locally cAMP and regulates $\Delta \Psi \mathrm{m}$ upon calcium overload. (a) Mitochondrial localization of the $4 \mathrm{mt}-E p a c-S^{\mathrm{H} 187}$ cAMP sensor in rat isolated neonatal cardiomyocytes. Confocal images of cardiomyocytes infected with $4 \mathrm{mt}-E$ Eac- $\mathrm{S}^{\mathrm{H} 187}$ (green) and stained with MitoTracker Red. The colocalization of $4 \mathrm{mt}-$ Epac$\mathrm{S}^{\mathrm{H} 187}$ with MitoTracker is shown in yellow. Bar scale, $10 \mu \mathrm{M}$. (b and $\mathbf{c}$ ) Representative kinetics of percentage increase in CFP/YFP recorded in rat neonatal cardiomyocytes infected with either $4 \mathrm{mt}-\mathrm{Epac}_{-} \mathrm{S}^{\mathrm{H} 187}$ (b) or Epac-S ${ }^{\mathrm{H} 187}$ sensor (c) and sequentially stimulated with $24 \mathrm{mM} \mathrm{HCO}_{3}^{-}, 25 \mu \mathrm{M}$ FSK and $20 \mu \mathrm{M}$ 8CPT-cAMP AM. (d) Representative kinetics of percentage increase in CFP/YFP recorded in rat neonatal cardiomyocytes infected with $4 \mathrm{mt}-E$ Eac- $\mathrm{S}^{\mathrm{H} 187}$ exposed to $25 \mu \mathrm{M} 2 \mathrm{HE}$ in the absence or presence of $24 \mathrm{mM}$ $\mathrm{HCO}_{3}^{-}$, and finally to $20 \mu \mathrm{M} 8 \mathrm{CPT}$-CAMP AM (b, $\left.n=19 ; \mathbf{c}, n=6 ; \mathbf{d}, n=7\right)$. (e) sAC expression in neonatal rat cardiomyocytes transfected with non-targeting small interfering RNA (siRNA) (si-Control) or SAC siRNA (si-sAC). (f) Representative confocal images of tetramethylrhodamine, methyl ester (TMRM)-labeled permeabilized neonatal rat cardiomyocytes transfected with si-Control or si-sAC at time $0 \mathrm{~s}$ (left) and $900 \mathrm{~s}$ (right) after $\mathrm{Ca}^{2+}(600 \mathrm{nM})$ addition. Bar scale, $50 \mu \mathrm{M}$. (g) Averaged values of mitochondrial membrane potential (measured as F/F0, where F is the TMRM fluorescence signal at $900 \mathrm{~s}$ and $\mathrm{F} 0$ is the signal at time $0 \mathrm{~s}$ of $\mathrm{Ca}^{2+}$ addition) $(n=50) .{ }^{* *} P<0.01$ versus si-Control 
a

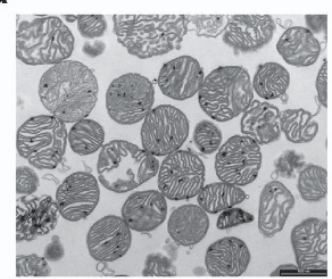

C

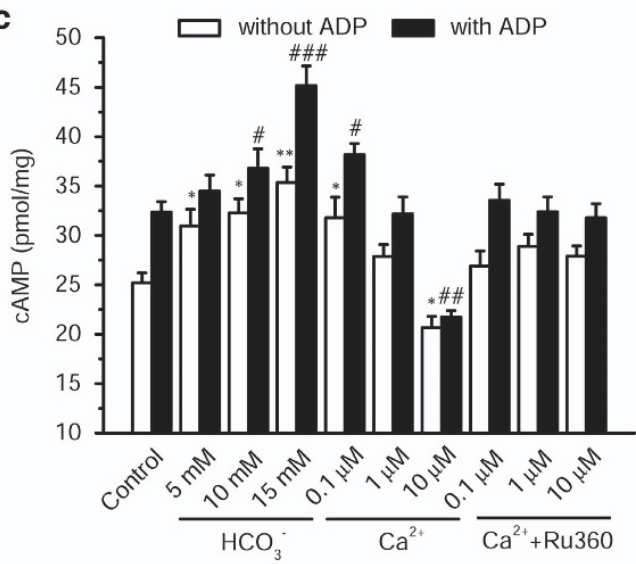

e

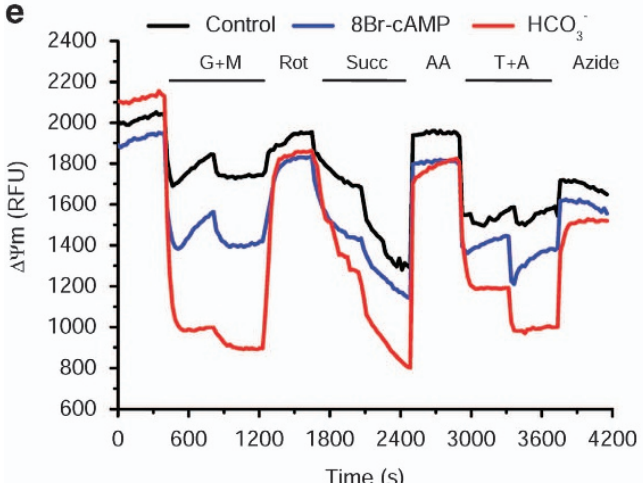

b

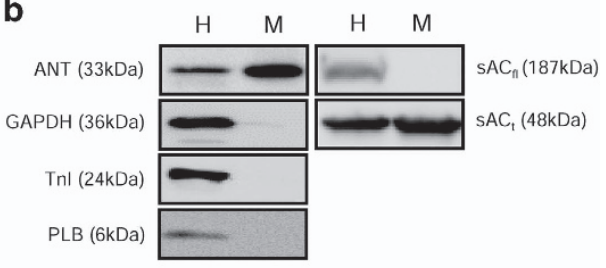

d

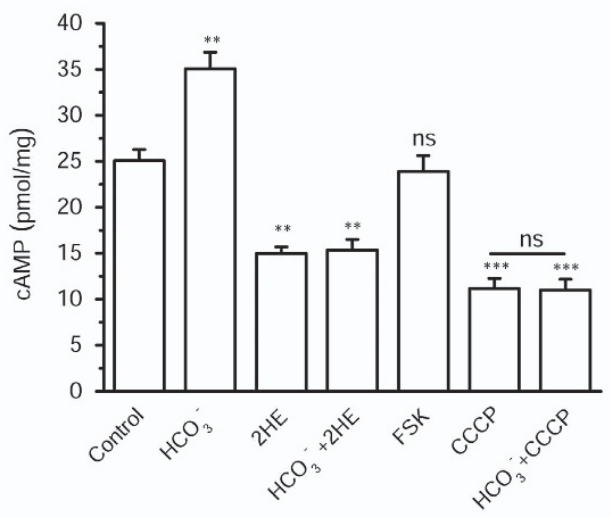

f

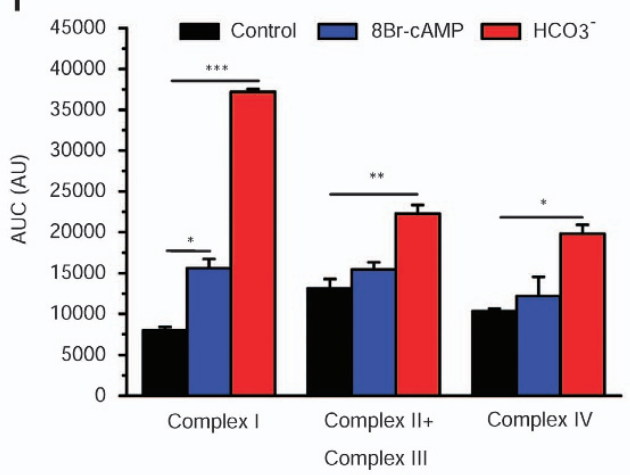

Figure 3 cAMP produced by SAC regulates mitochondrial transmembrane inner potential $(\Delta \Psi \mathrm{m})$. (a) Transmission electron microscopy image of isolated subsarcolemmal mitochondria from rat heart ventricles. Bar scale, $1 \mu \mathrm{M}$. (b) Purity analysis of mitochondrial fraction by western blot. Protein ANT, inner membrane; glyceraldehyde 3-phosphate dehydrogenase (GAPDH), cytosol; PLB, sarcoplasmic reticulum; Tnl; myofibrils; $s \mathrm{SC}_{\mathfrak{f l}}$ and $s \mathrm{SC}_{\mathrm{t}}$ were probed in heart homogenate $(\mathrm{H})$ and mitochondria $(\mathrm{M})$. Results are representative of three independent experiments. (c) cAMP levels produced in isolated mitochondria in the presence of $\mathrm{HCO}_{3}^{-}, \mathrm{Ca}^{2+}$ and $\mathrm{Ca}^{2+}+\mathrm{Ru}^{2} 60$ (a MCU inhibitor, $1 \mathrm{nM}$ ), under basal condition or upon stimulation with $1.65 \mathrm{mM}$ ADP, determined by enzyme-linked immunosorbent assay (ELISA) $(n=4-5)$. (d) cAMP levels in isolated mitochondria under basal condition or in the presence of $15 \mathrm{mM} \mathrm{HCO}_{3}^{-}, 25 \mu \mathrm{M} 2 \mathrm{HE}, \mathrm{HCO}_{3}^{-}+2 \mathrm{HE}, 25 \mu \mathrm{M} \mathrm{FSK}, 5 \mu \mathrm{M} \mathrm{CCCP}$ or CCCP+HCO ${ }_{3}^{-}$, determined by ELISA. Control, untreated mitochondria; NS, not significant $(n=3-7)$. (e) $\Delta \Psi \mathrm{m}$ was evaluated with Rhod123 fluorescence in the absence or presence of $1 \mathrm{mM} 8 \mathrm{Br}-\mathrm{CAMP}^{-}$or $15 \mathrm{mM} \mathrm{HCO}-$ in isolated cardiac mitochondria with different respiratory substrates: $0.25 \mathrm{mM}$ malate $(\mathrm{M})$ and $0.5 \mathrm{mM}$ glutamate $(\mathrm{G}$ ) for complex I (inhibited by $2 \mu \mathrm{M}$ rotenone (Rot)); $0.5 \mathrm{mM}$ succinate (Succ) for complexes II and III (blocked by the complex III inhibitor antimycin A (AA), $0.25 \mu \mathrm{g} / \mathrm{ml}$ ) and $0.05 \mathrm{mM} \mathrm{TMPD} \mathrm{(T)} \mathrm{with} 0.2 \mathrm{mM}$ ascorbate (A) for complex IV (inhibited by $5 \mathrm{mM}$ sodium azide). RFU, relative fluorescence unit. (f) Comparison of $8 \mathrm{Br}-\mathrm{CAMP}$ and $\mathrm{HCO}_{3}^{-}$effects on $\triangle \Psi \mathrm{m}$ stimulated with various respiratory substrates. Areas under the curve (AUC) were calculated from experiments such as that shown in (e) $(n=3)$. AU, arbitrary units. ${ }^{\star} P<0.05,{ }^{* \star} P<0.01,{ }^{* \star \star} P<0.001$ versus Control; ${ }^{\sharp} P<0.05$, ${ }^{\# \#} P<0.01$ versus Control with $\mathrm{ADP}$

FSK had no stimulatory effect on cAMP in isolated mitochondria, confirming clearly the absence of tmAC within mitochondria (Figure 3d).

cAMP increases $\Delta \Psi \mathrm{m}$, respiration and ATP levels. Next, the $\Delta \Psi \mathrm{m}$ was montored with the probe, rhodamine 123 (Rhod123), in the presence of various respiratory substrates (Figures $3 e$ and $\mathrm{f}$ ). We used 8Br-cAMP, a membranepermeant cAMP analog, as a control, and $\mathrm{HCO}_{3}^{-}$to stimulate endogenous production of cAMP. Figure $3 e$ shows that 8Br-cAMP slightly hyperpolarized mitochondria in condition of complex I-driven respiration, but failed to have any effect in the presence of respiratory substrates for complexes II-IV. In contrast, $\mathrm{HCO}_{3}^{-}$triggered a hyperpolarization in all conditions of substrates (Figure 3f). This hyperpolarization was accompanied by an increase in oxygen consumption in response to $\mathrm{HCO}_{3}^{-}$(Figure 4a). Finally, when mitochondria were stimulated by $\mathrm{HCO}_{3}^{-}$or $\mathrm{Ca}^{2+}$, this led to an increase in 

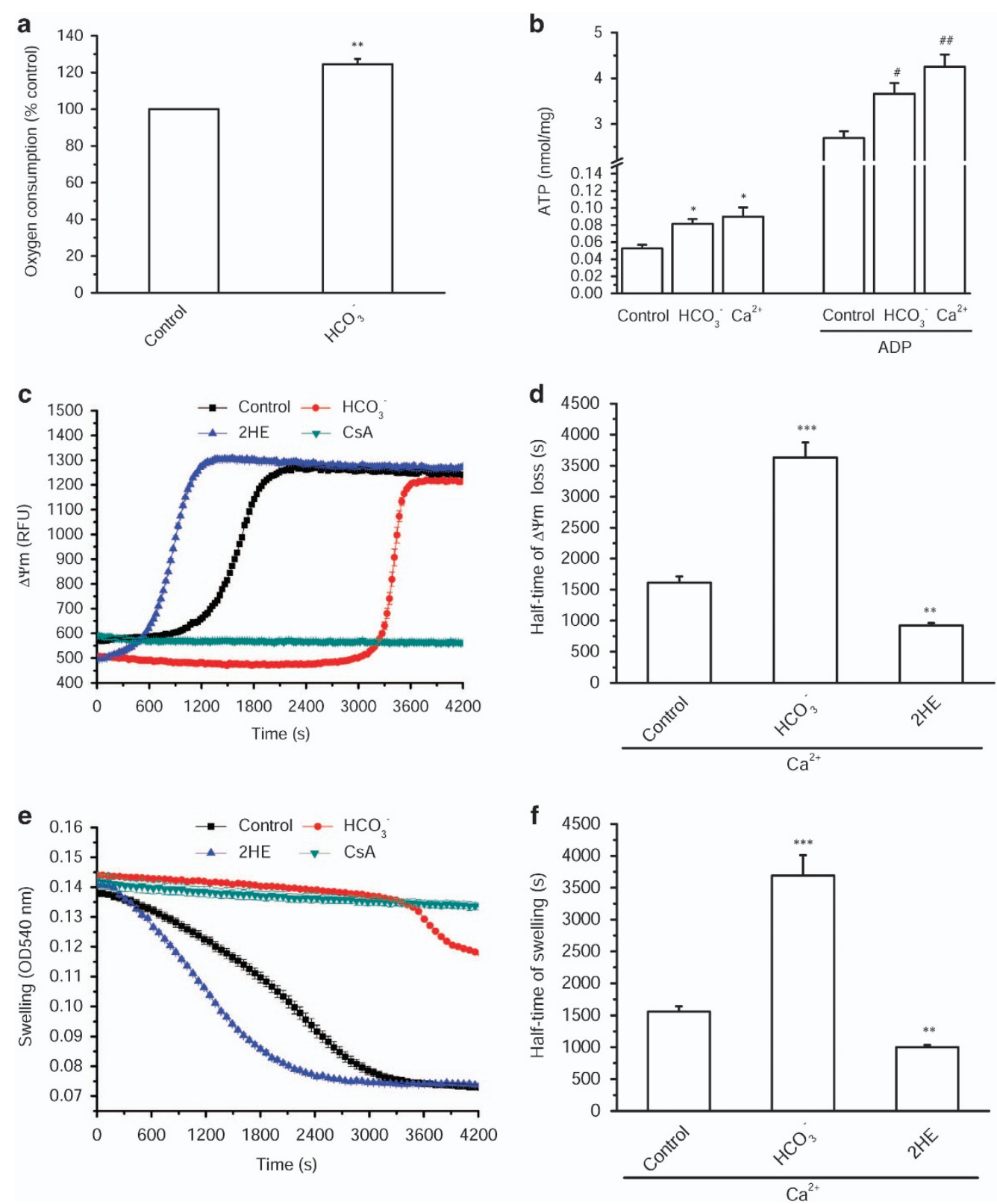

Figure 4 cAMP regulates mitochondrial respiration, ATP levels and $\mathrm{Ca}^{2+}$ induced mitochondrial depolarization and swelling. (a) Oxygen consumption of mitochondria measured with the probe MitoXpress in the presence or absence of $15 \mathrm{mM} \mathrm{HCO}_{3}^{-}$driven by $2.5 \mathrm{mM}$ malate and $5 \mathrm{mM}$ glutamate with $1.65 \mathrm{mM}$ ADP. Control was normalized at $100 \%(n=5)$. (b) ATP production in the presence of $15 \mathrm{mM} \mathrm{HCO}_{3}^{-}$and $0.1 \mu \mathrm{M} \mathrm{Ca}^{2+}$ with or without $1.65 \mathrm{mM} \mathrm{ADP}$ stimulation driven by $5 \mathrm{mM}$ succinate $(n=4)$. ${ }^{*} P<0.05$ versus Control; ${ }^{\#} P<0.05,{ }^{\#} P<0.01$ versus Control with ADP. (c) Effect of $15 \mathrm{mM} \mathrm{HCO}_{3}^{-}, 25 \mu \mathrm{M} 2 \mathrm{HE}$ and $5 \mu \mathrm{M}$ CsA on $\Delta \Psi \mathrm{m}$ loss induced by $10 \mu \mathrm{M} \mathrm{Ca}^{2+}$. (d) Average half-time values of $\Delta \Psi \mathrm{m}$ loss induced by $10 \mu \mathrm{M} \mathrm{Ca}^{2+}$ calculated from panels (c) ( $\left.n=7-20\right)$. (e) Effect of $15 \mathrm{mM} \mathrm{HCO}_{3}^{-}, 25 \mu \mathrm{M} 2 \mathrm{HE}$ and $5 \mu \mathrm{M}$ CsA on mitochondrial swelling induced by $10 \mu \mathrm{M}$ $\mathrm{Ca}^{2+}$. (f) Average half-time values of mitochondrial swelling induced by $10 \mu \mathrm{M} \mathrm{Ca}{ }^{2+}$ calculated from panel $\mathbf{e}(n=7-20)$. ${ }^{* \star} P<0.01,{ }^{* \star *} P<0.001$ versus Control

ATP production both in the absence and presence of ADP (Figure $4 \mathrm{~b}$ ). These data indicate that cAMP produced by a mitochondrial SAC stimulates the oxidative phosphorylation increasing $\Delta \Psi \mathrm{m}$ and mitochondrial ATP synthesis.

cAMP delays $\mathbf{C a}^{2+}$-induced MPT. We hypothesized that the cyclic nucleotide could have a role in the regulation of MPT. ${ }^{39}$ In isolated cardiac mitochondria, MPT can be elicited by $10 \mu \mathrm{M} \mathrm{Ca}^{2+}$ and prevented by $5 \mu \mathrm{M} \mathrm{CsA}$ and detected as a loss of $\Delta \Psi \mathrm{m}$ and a matrix swelling. ${ }^{37}$ We used two robust miniaturized assays ${ }^{37,40}$ to concomitantly measure the effect of SAC inhibition by $25 \mu \mathrm{M} 2 \mathrm{HE}$ on mitochondrial depolarization (Figures $4 \mathrm{c}$ and $\mathrm{d}$ ) and matrix swelling (Figures $4 \mathrm{e}$ and $\mathrm{f}$ ) induced by $10 \mu \mathrm{M} \mathrm{Ca}{ }^{2+}$. SAC inhibition by $2 \mathrm{HE}$ accelerated the depolarization (Figures $4 \mathrm{c}$ and $\mathrm{d}$ ) and swelling (Figures $4 \mathrm{e}$ and $\mathrm{f}$ ) induced by $\mathrm{Ca}^{2+}$, as shown by the decreased half-time of $\Delta \psi_{\mathrm{m}}$ loss and swelling (Figures $4 \mathrm{~d}$ and f). Conversely, $15 \mathrm{mM} \mathrm{HCO}_{3}^{-}$slowed both processes (Figures $4 \mathrm{~d}$ and $\mathrm{f}$ ), suggesting that cAMP elevation confers a protection of mitochondria from $\mathrm{Ca}^{2+}$-induced MPT. 
a

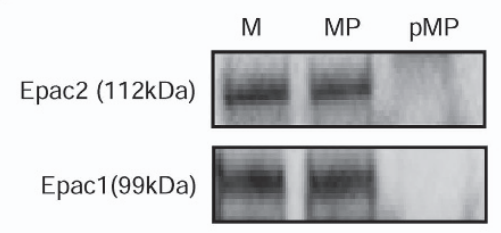

C

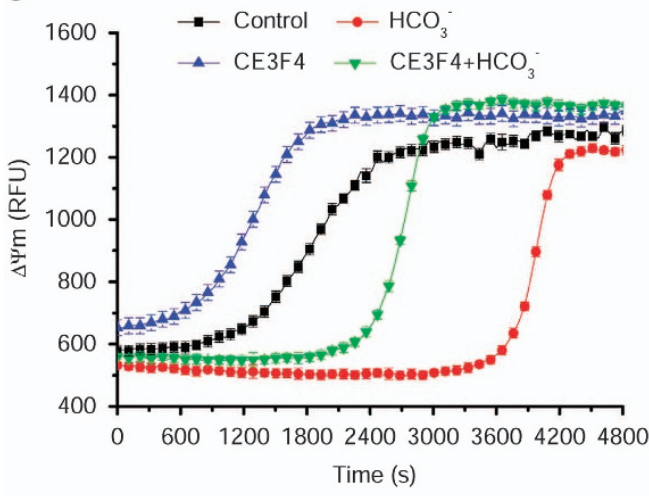

e

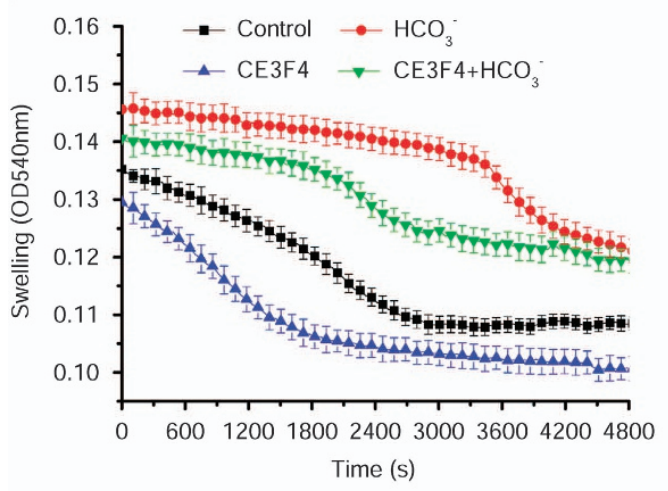

b

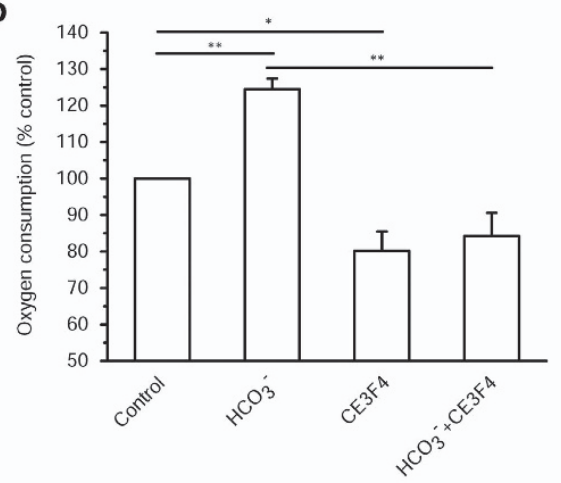

d

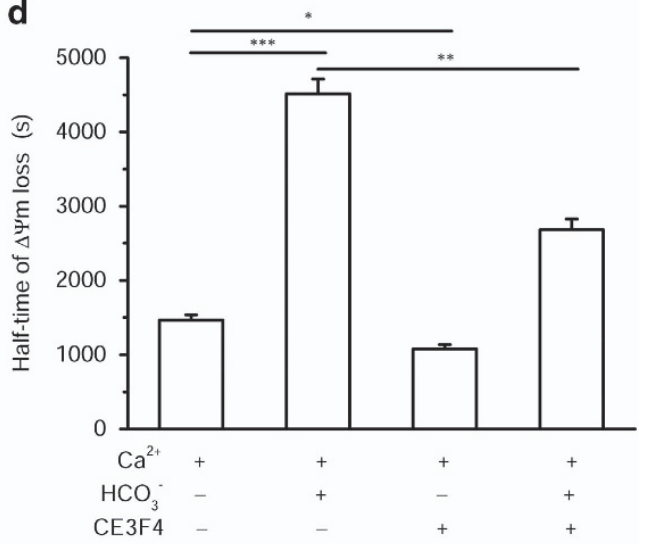

f

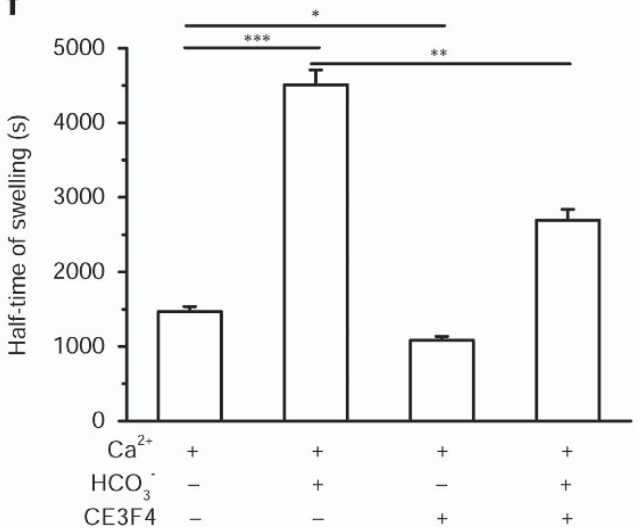

Figure 5 Epac1 mediates cAMP effect on respiration and permeability transition. (a) Western blot analysis of Epac1 and Epac2 isoforms in mitochondria (M), mitoplast (MP) and postmitoplast fraction (pMP). (b) Oxygen consumption measurement with the MitoXpress probe in the absence or presence of $15 \mathrm{mM} \mathrm{HCO}_{3}^{-}, 50 \mu \mathrm{M} \mathrm{CE} 3 \mathrm{~F} 4$ and $\mathrm{HCO}_{3}^{-}+\mathrm{CE} 3 F 4$. Control, untreated mitochondria, has been normalized to $100 \%(n=5)$. (c) Effects of CE3F4 on $\Delta \Psi \mathrm{m}$ induced by $10 \mu \mathrm{M} \mathrm{Ca}{ }^{2+}$. (d) Average half-time values of $\Delta \Psi \mathrm{m}$ loss induced by $10 \mu \mathrm{M} \mathrm{Ca}{ }^{2+}$ calculated from experiments such as that shown in (c) $(n=15)$. (e) Effects of CE3F4 on mitochondrial swelling induced by $10 \mu \mathrm{M}$ Ca ${ }^{2+}$. (f) Average half-time values of mitochondrial swelling induced by $10 \mu \mathrm{M} \mathrm{Ca}^{2+}$ calculated from experiments such as that shown in $(e)(n=15) .{ }^{*} P<0.05,{ }^{* *} P<0.01,{ }^{* \star *} P<0.001$ versus Control

Mitochondrial cAMP effects are independent of PKA. cAMP effects are classically mediated by activation of two main effectors, PKA and Epac to regulate a plethora of biological functions in the heart. ${ }^{19}$ In mitochondria, PKA has been reported to be associated with outer membrane (OM) or to be in the matrix for controlling mitochondrial dynamics and oxidative metabolism. ${ }^{35,41,42}$ We thus examined whether PKA was involved in the mitochondrial cAMP effects by testing the effects of two different pharmacological PKA inhibitors, H89 and KT5720, on the induction of MPT by $\mathrm{Ca}^{2+}$. As shown in
Supplementary Figure 1, these inhibitors had no significant effect on $\Delta \Psi \mathrm{m}$ and swelling, indicating that PKA may not be involved in MPT regulation.

Epac1 mediates cAMP effect on respiration and MPT. Then, we checked the expression of Epac isoforms. As shown in Figure 5a, both Epac1 and Epac2 isoforms were found in isolated cardiac mitochondria as well as in mitoplasts generated by osmotic shock, but were absent in the postmitoplast supernatant. This suggests that Epac can be 
anchored to the IM facing the mitochondrial matrix or the intermembrane space or localized in the matrix.

To evaluate the functional role of Epac, we used three pharmacological Epac inhibitors exhibiting different specificities and tested their effects on $\mathrm{Ca}^{2+}$-induced depolarization and swelling as well as oxygen consumption. We used ESIO9, a pan-Epac inhibitor, ESI05, an Epac2-selective inhibitor, ${ }^{21,43}$ and CE3F4, an Epac1-selective inhibitor. ${ }^{44}$ As shown in Figure 5b, Epac1 inhibition with $50 \mu \mathrm{M}$ CE3F4 decreased basal oxygen consumption and also prevented the stimulatory effect of $\mathrm{HCO}_{3}^{-}$. Moreover, CE3F4 accelerated $\mathrm{Ca}^{2+}$-induced depolarization (Figures $5 \mathrm{c}$ and $\mathrm{d}$ ) and swelling (Figures $5 \mathrm{e}$ and f). Similar findings were obtained with ESI09 but not with ESI05 (Supplementary Figure 2). These data thus point to Epac1 as a key effector in mitochondrial cAMP effects.

Next, we tested the effect of Epac1 on the level of matrix $\mathrm{Ca}^{2+}$ using the Rhod-2 probe, and CGP37157, a mitochondrial $\mathrm{Na}^{+} / \mathrm{Ca}^{2+}$ exchanger ( $\mathrm{mNCX}$ ) inhibitor, appeared to accelerate $\mathrm{Ca}^{2+}$ entry in isolated mitochondria (Figures $6 \mathrm{c}$ and d). This effect was similar to that of CE3F4. However, the combination of both inhibitors produced an additive effect, suggesting that they act via two distinct mechanisms. Thus, it is unlikely that Epac1 regulates $\mathrm{mNCX}$. To examine the role of $\mathrm{MCU}$, we used RU360, a highly specific MCU inhibitor. As anticipated, RU360 (from 0.2 to $1 \mathrm{nM}$ ) induced a dose-dependent inhibition of $\mathrm{Ca}^{2+}$ entry (Supplementary Figure 3). Interestingly, inhibition of Epac in the presence of non-maximal concentrations of RU360 partially restored $\mathrm{Ca}^{2+}$ entry within mitochondria (Figures 6e and f and Supplementary Figure 3), but this effect was abrogated when the MCU was fully inhibited with $1 \mathrm{nM}$ RU360 (Supplementary Figure 3a). These results suggest that $\mathrm{MCU}$ is the major effector of Epac1 for the regulation of mitochondrial $\mathrm{Ca}^{2+}$ movements.

Epac1 mediates mitochondrial $\mathrm{Ca}^{2+}$ accumulation and $\Delta \Psi \mathrm{m}$ loss in cardiomyocytes. The Epac1 silencing by siRNA indicated that a decreased level of Epac1 in neonatal rats decreased $\Delta \Psi_{\mathrm{m}}$ (Figures $7 \mathrm{a}$ and $\mathrm{c}$ ) and in parallel accelarated the mitochondrial calcium entry (Figures 7d and e), as does the inhibitor CE3F4 in adult permeabilized cardiomyocytes upon addition of $\mathrm{Ca}^{2+}$ (Figures $7 \mathrm{f}$ and $\mathrm{g}$ ). At this concentration, $\mathrm{Ca}^{2+}$ did not affect $\Delta \Psi \mathrm{m}$, avoiding any artifact since most ions and metabolites transports are dependent of the $\Delta \Psi_{\mathrm{m}}$ (Supplementary Figures $4 \mathrm{a}$ and $\mathrm{b}$ ). We also checked that our conditions of fluorescence excitation did not trigger MPT (Supplementary Figures 4c and $d$ ). Altogether, these results suggest that Epac1 has a role in reducing the entry of $\mathrm{Ca}^{2+}$ in mitochondria, and then indirectly stabilizes the $\Delta \Psi \mathrm{m}$ in primary cardiomyocytes.

The mitochondrial cAMP pathway can prevent MPT in HF rat model. To evaluate the ability of the mitochondrial cAMP pathway to regulate MPT in a pathological model, we induced $\mathrm{HF}$ in rats by transverse aortic constriction (TAC) during 22 weeks. ${ }^{45}$ As shown in Supplementary Figure $5 \mathrm{a}$, TAC rats showed a strong cardiac and lung hypertrophy. Accordingly, cardiac function and the fractional shortening of the left ventrice were diminished (Supplementary Figures 5b and c). Expression level of various proteins was analyzed in heart ventricle homogenates and mitochondrial fraction. As shown in Figures $8 \mathrm{a}$ and $\mathrm{b}, \mathrm{sAC}_{\mathrm{t}}$ protein expression was reduced and Epac1 expression was increased in homogenate and mitochondria from HF as compared with sham hearts. MCU expression was similar in mitochondrial fraction from HF and sham rats. To explore how HF affects mitochondrial $\mathrm{Ca}^{2+}$-induced MPT, $\mathrm{Ca}^{2+}$-induced mitochondrial depolarization and $\mathrm{Ca}^{2+}$ accumulation was measured in isolated mitochondria from HF and sham rats. As shown in Figures $8 \mathrm{c}$ and $\mathrm{d}$ and Supplementary Figures $6 \mathrm{a}-\mathrm{d}, \mathrm{Ca}^{2+}$ induced a faster depolarization and $\mathrm{Ca}^{2+}$ uptake in $\mathrm{HF}$ than in sham mitochondria. In line with this, $\mathrm{Ca}^{2+}$ induced a faster mitochondrial swelling in HF than in sham mitochondria (Figure $8 \mathrm{e}$ and Supplementary Figures $6 \mathrm{e}$ and $\mathrm{f}$ ). This confirms that MPT is altered in HF, which could make mitochondria more vulnerable to $\mathrm{Ca}^{2+}$ overload. ${ }^{46}$ Interestingly, mitochondria from $\mathrm{HF}$ rats still responded to $\mathrm{HCO}_{3}^{-}$ stimulation of mitochondrial cAMP production by $\mathrm{SAC}$, by delaying $\triangle \Psi \mathrm{m}$ loss, $\mathrm{Ca}^{2+}$ entry and MPT (i.e. matrix swelling). These effects were blunted by SAC or Epac1 inhibition with CE3F4 (Figures 8c-e and Supplementary Figures 6a-f).

\section{Discussion}

In this study, we characterized a functional cAMP pathway within the mitochondria of neonatal and adult cardiomyocytes, which can regulate mitochondrial function and cell death. cAMP is locally produced within the mitochondria by a $\mathrm{Ca}^{2+} / \mathrm{HCO}_{3}^{-}$-sensitive $\mathrm{sAC}_{\mathrm{t}}$ and activates Epac1 to stimulate oxidative metabolism while preventing MPT by limiting mitochondrial $\mathrm{Ca}^{2+}$ accumulation via $\mathrm{MCU}$. As $\mathrm{HCO}_{3}^{-}$production can be catalyzed by carbonic anhydrase from $\mathrm{CO}_{2}$ and $\mathrm{H}_{2} \mathrm{O}, \mathrm{CO}_{2}$ being produced by the Krebs cycle and the pyruvate deshydrogenase inside mitochondrial matrix, our data thus link, for the first time, mitochondrial metabolism, cAMP and cell death in the heart, independently of cytosolic cAMP signaling.

Our data are in good agreement with pioneer studies revealing the existence of a mitochondrial cAMP signaling in various cell types. ${ }^{27-29}$ Prompted by the observation that a G-protein- and FSK-insensitive SAC is present in various organelles, ${ }^{38,47-49}$ Acin-Perez et al. $^{27}$ discovered a $\mathrm{CO}_{2}-\mathrm{HCO}_{3}^{-}$-sAC-cAMP-PKA (mito-sAC) signaling cascade entirely contained within the mitochondria. This mito-sAC cascade serves as a metabolic sensor modulating ATP generation and ROS production in response to nutrient availability. ${ }^{29}$ By targeting the recently developed Epac-S ${ }^{\mathrm{H} 187}$ cAMP FRET sensor ${ }^{36}$ to the mitochondria, we showed that $\mathrm{SAC}$ activation by $\mathrm{HCO}_{3}^{-}$increases mitochondrial cAMP in neonatal cardiomyocytes, as shown earlier in HeLa and $\mathrm{CHO}$ cells. ${ }^{35}$ We showed that the constitutive mitochondrial CAMP signaling pathway regulates $\Delta \Psi \mathrm{m}$ and MPT not only in healthy but also in failing heart mitochondria and that these functions are mediated by Epac1.

A functional mito-sAC pathway in mitochondria from adult heart. Although it was already known that SAC can be localized into mitochondria, ${ }^{4-49}$ little was known about their biological function in the organelle. Here, we identified endogenous $\mathrm{sAC}_{t}$ in cardiac mitochondria and mitoplasts. We showed for the first time that increasing intramitochondrial cAMP level delays the onset of MPT, while stimulating oxygen consumption. Although $\mathrm{HCO}_{3}^{-}$and $\mathrm{Ca}^{2+}$ enhanced 

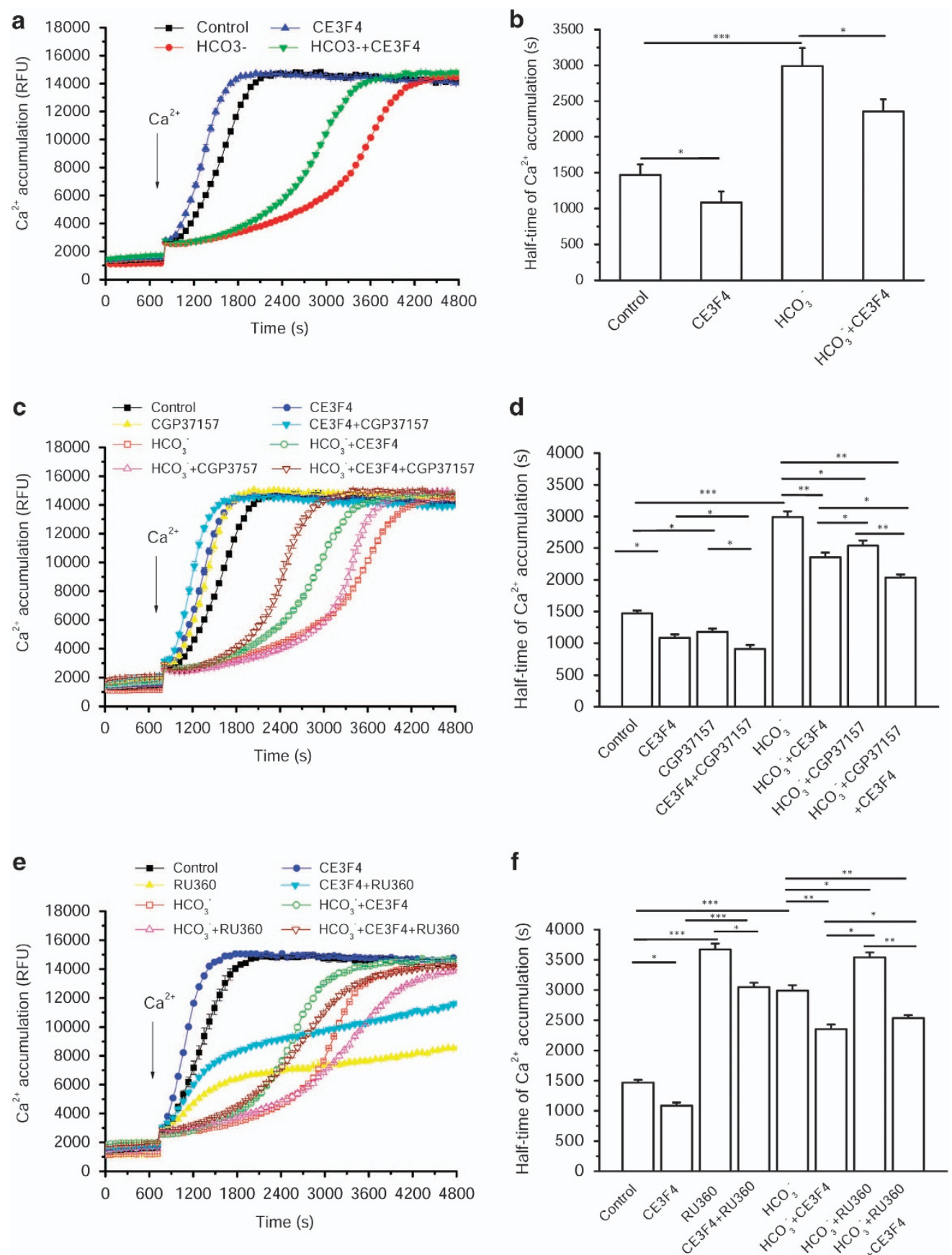

Figure 6 Epac1 prevents $\mathrm{Ca}^{2+}$ entry into mitochondria via the $\mathrm{Ca}^{2+}$ uniporter and not the $\mathrm{Na}^{+} / \mathrm{Ca}^{2+}$ exchanger. (a) Measurement of $\mathrm{Ca}^{2+}$ accumulation in isolated mitochondria using Rhod-2. $\mathrm{HCO}_{3}^{-}$was used at $15 \mathrm{mM}$, and CE3F4 was used at $50 \mu \mathrm{M}$. (b) Half-time of $\mathrm{Ca}^{2+}$ entry into mitochondria calculated from experiments such as that shown in (a) $(n=5)$. (c) Time course of $\mathrm{Ca}^{2+}$ accumulation in isolated mitochondria in the presence of $15 \mathrm{mM} \mathrm{HCO}_{3}^{-}, 50 \mu \mathrm{M} \mathrm{CE3F4} \mathrm{and} 10 \mu \mathrm{M} \mathrm{CGP37157}$ (a mNCX inhibitor). (d) Half-time of $\mathrm{Ca}^{2+}$ accumulation into mitochondria calculated from experiments such as that shown in (c) $(n=5)$. (e) Time course of $\mathrm{Ca}^{2+}$ accumulation in isolated mitochondria in the presence of $15 \mathrm{mM} \mathrm{HCO}_{3}^{-}, 50 \mu \mathrm{M} \mathrm{CE3F4}$ and $0.4 \mathrm{nM}$ Ru360 (a MCU inhibitor). (f) Half-time of $\mathrm{Ca}^{2+}$ accumulation into mitochondria calculated from experiments such as that shown in (e) $(n=5) .{ }^{*} P<0.05,{ }^{* *} P<0.01$ and ${ }^{* * *} P<0.001$

CAMP production, $\mathrm{HCO}_{3}^{-}$was more potent than $\mathrm{Ca}^{2+}$, which is in line with the fact that $\mathrm{HCO}_{3}^{-}$and $\mathrm{Ca}^{2+}$ stimulatory effects are not redundant: $\mathrm{HCO}_{3}^{-}$modulates the active site of SAC, whereas $\mathrm{Ca}^{2+}$ increases ATP affinity. ${ }^{27}$ Interestingly, a specific inhibitor of SAC, $2 \mathrm{HE}$, totally prevented the effects of $\mathrm{HCO}_{3}^{-}$and $\mathrm{Ca}^{2+}$, indicating that $\mathrm{SAC}$ may be the unique source of mitochondrial cAMP.
Effectors of mitochondrial cAMP. While PKA is the canonical mediator of cAMP in a number of cell functions and cell subcompartments, and was shown earlier to regulate mitochondrial ATP and ROS production, ${ }^{27,29,50,51}$ PKA was clearly not involved in the induction of MPT by $\mathrm{Ca}^{2+}$ as $\mathrm{H} 89$ and KT5720 failed to modulate it. We thus focused our interest on Epac, because it emerged in the past decade as 
a si-Control si-Epac1

Epac1(99kDa)

GAPDH (36kDa)

b
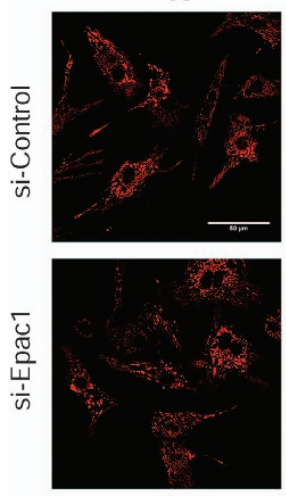

d
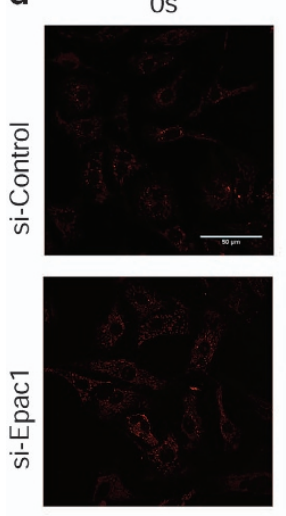

f
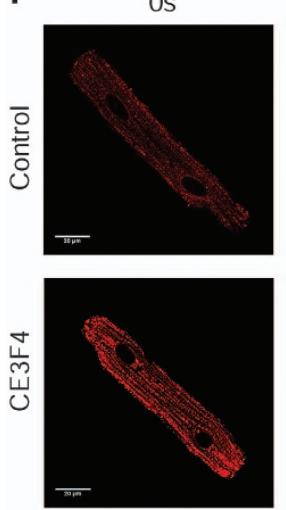

900s
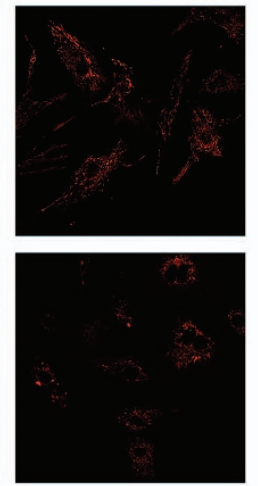

600s
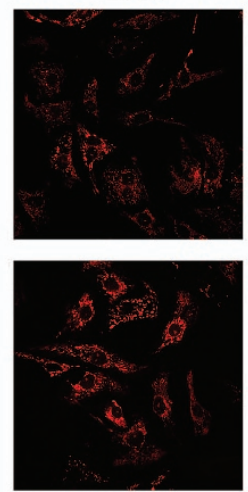

600s
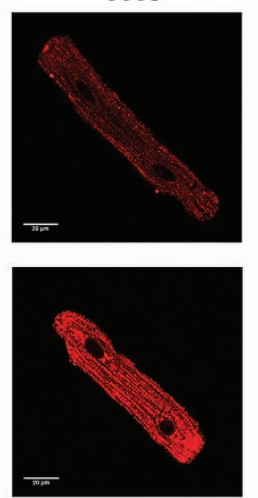

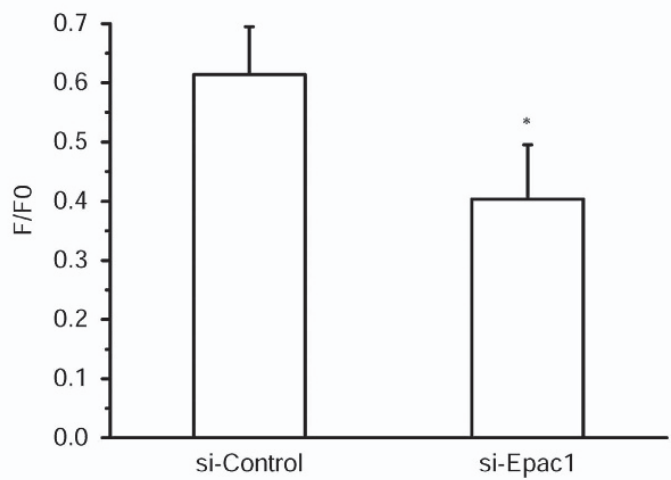

e

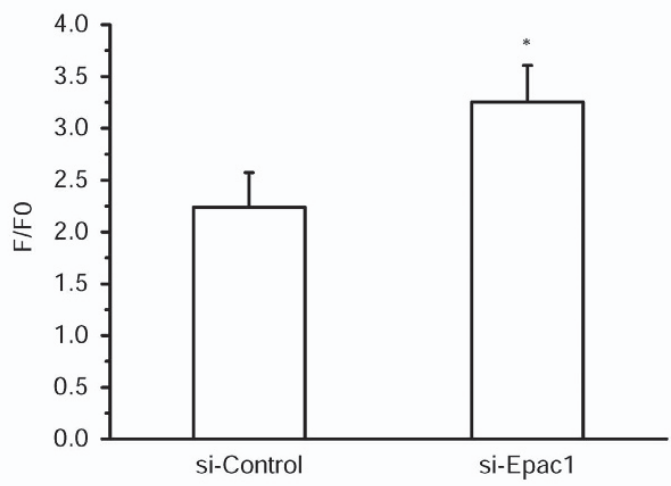

g

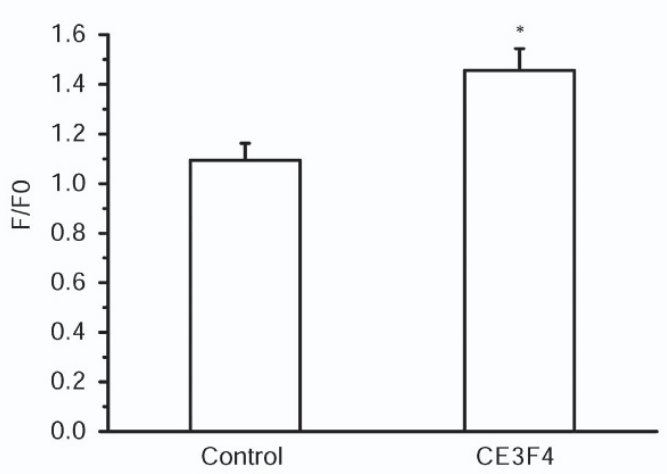

Figure 7 Epac1 mediates mitochondrial calcium accumulation and $\Delta \Psi \mathrm{m}$ loss in cellulo. (a) Epac1 expression in neonatal rat cardiomyocytes transfected with non-targeting small interfering RNA (siRNA) (si-Control) or Epac1 siRNA (si-Epac1). (b) Representative confocal images of TMRM-labeled permeabilized neonatal rat cardiomyocytes transfected with si-Control or si-Epac1 at time $0 \mathrm{~s}$ (left) and $900 \mathrm{~s}$ (right) after $\mathrm{Ca}^{2+}(600 \mathrm{nM}$ ) addition. Bar scale, $50 \mu \mathrm{M}$. (c) Averaged values of $\Delta \Psi \mathrm{m}$ (measured as F/F0, where $\mathrm{F}$ is the TMRM fluorescence signal at $900 \mathrm{~s}$ and $\mathrm{F} 0$ is the signal at time $0 \mathrm{~s}$ of $\mathrm{Ca}^{2+}$ addition) $(n=36)$. (d) Representative confocal images of Rhod-2 AM-labeled permeabilized neonatal rat cardiomyocytes transfected with si-Control or si-Epac1 at time $0 \mathrm{~s}$ (left) and $600 \mathrm{~s}$ (right) after $\mathrm{Ca}^{2+}(200 \mathrm{nM})$ addition. Bar scale, $50 \mu \mathrm{M}$. (e) Averaged values of intramitochondrial $\mathrm{Ca}^{2+}$ accumulation (measured as F/FO, where $\mathrm{F}$ is the Rhod-2 fluorescence signal at $600 \mathrm{~s}$ and $\mathrm{F} 0$ is the signal at time $0 \mathrm{~s}$ of $\mathrm{Ca}^{2+}$ addition) $(n=30)$. (f) Representative confocal images of Rhod-2 AM-labeled permeabilized adult rat ventricular myocytes at time $0 \mathrm{~s}$ (left) and $600 \mathrm{~s}$ (right) after $\mathrm{Ca}^{2+}(200 \mathrm{nM}$ ) addition in the absence (top) or presence (bottom) of CE3F4. Bar scale, $20 \mu \mathrm{M}$. (g) Averaged values of intramitochondrial $\mathrm{Ca}^{2+}$ accumulation (measured as F/F0, where $\mathrm{F}$ is the Rhod-2 fluorescence signal at $600 \mathrm{~s}$ and $\mathrm{F} 0$ is the signal at time $0 \mathrm{~s}$ of $\mathrm{Ca}^{2+}$ addition) $(n=10) .{ }^{*} P<0.05$ versus si-Control or Control 
a

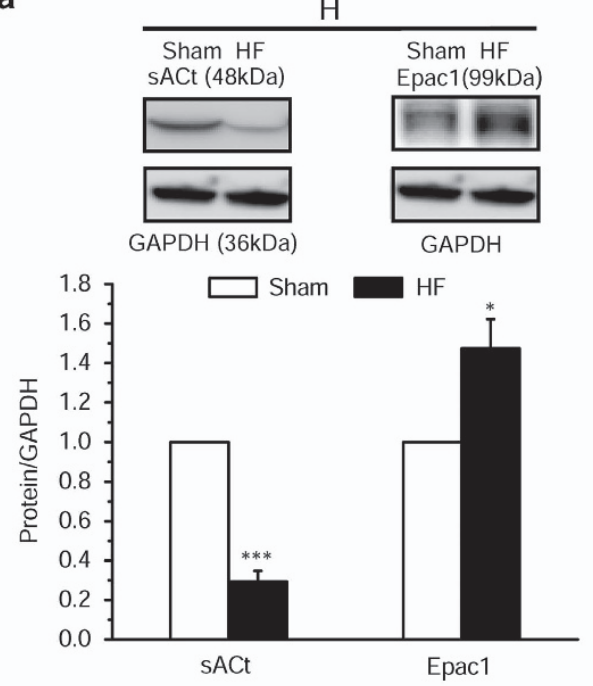

c
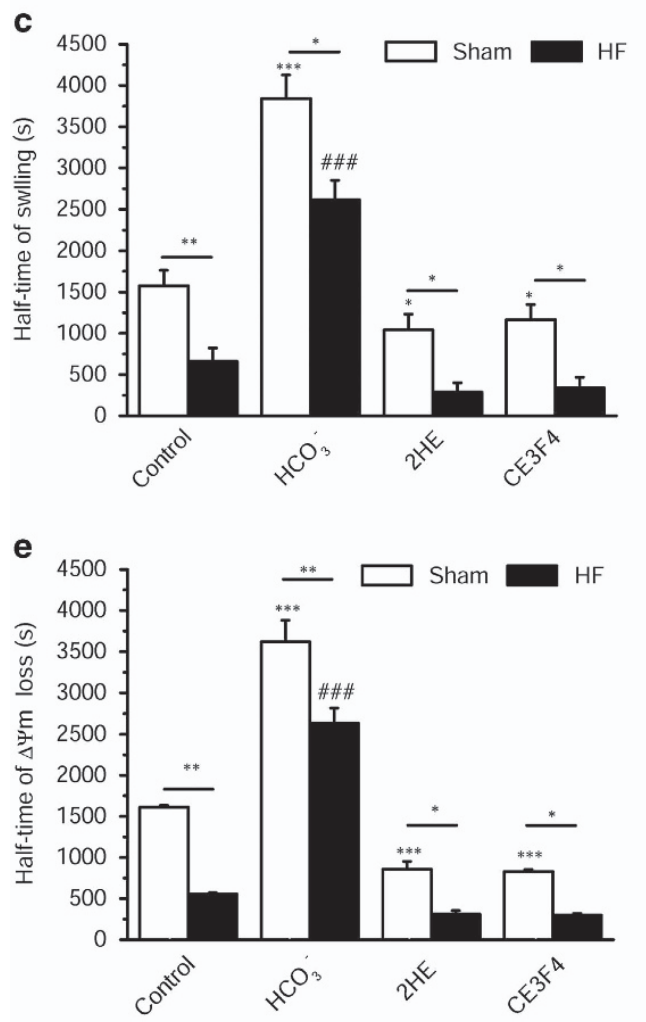

b

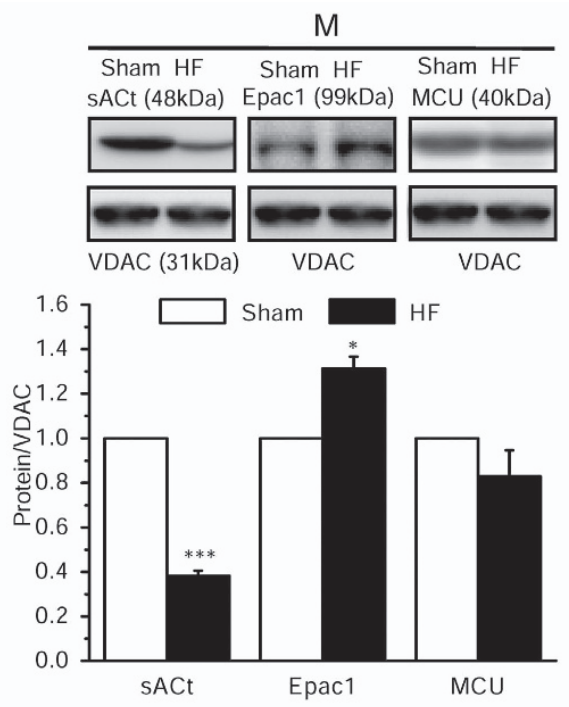

d

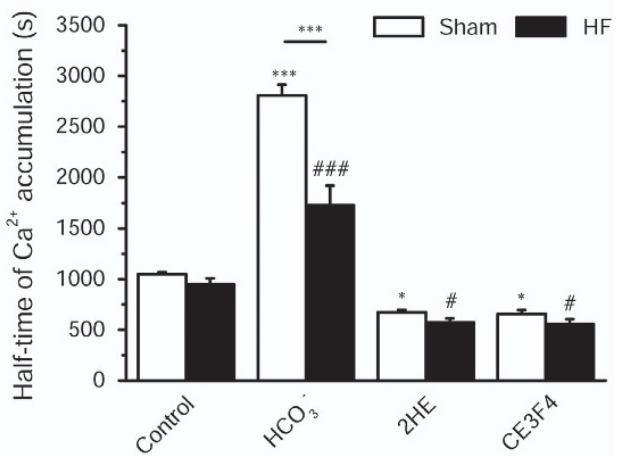

f

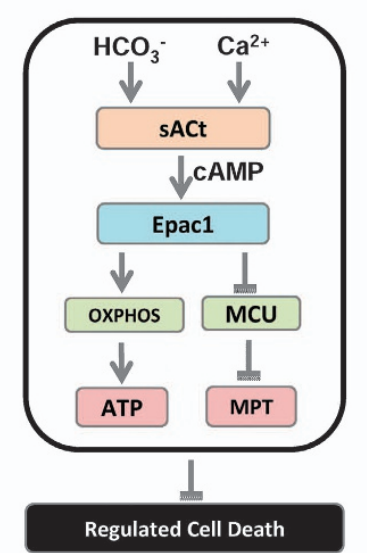

Figure 8 Expression levels of SACt, Epac1 and MCU in hearts and mitochondria isolated from sham and HF rats and cAMP regulation of $\triangle \Psi \mathrm{m}$ and $\mathrm{Ca}^{2+}$ uptake. (a) Expression level of SAC and Epac1 in sham (white bars) and HF (black bars) heart homogenates (H) normalized by glyceraldehyde 3-phosphate dehydrogenase (GAPDH). Representative western blot images are shown on top (sham on left and $\mathrm{HF}$ on right). (b) Expression level of $\mathrm{SAC}_{\mathrm{t}}$, Epac1 and MCU proteins relative to voltage-dependent anion channel (VDAC) in isolated mitochondria (M) in HF versus sham. Representative blots are shown on top (sham on left and HF on right). Data are mean \pm S.E.M. of four sham and four $\mathrm{HF}$ rats, detected in four independent immunoblots. (c) Half-time of $\Delta \Psi \mathrm{m}$ loss induced by $10 \mu \mathrm{M} \mathrm{Ca}^{2+}$ calculated from experiments such as shown in Supplementary Figures $6 \mathrm{a}$ and b. (d) Half-time of $\mathrm{Ca}^{2+}$ accumulation calculated from experiments such as shown in Supplementary Figures $6 \mathrm{c}$ and d. (e) Half-time of swelling induced by $10 \mu \mathrm{M} \mathrm{Ca}^{2+}$ calculated from experiments such as that shown in Supplementary Figures $6 \mathrm{e}$ and $\mathrm{f} .{ }^{\star} P<0.05,{ }^{* \star} P<0.01,{ }^{* \star \star} P<0.001$ versus sham control; ${ }^{\#} P<0.05$, ${ }^{\# \# \# ~} P<0.001$ versus $\mathrm{HF}$ control $(n=4)$. (f) Hypothetical scheme showing the local role of mitochondrial $\mathrm{CAMP}$ signaling pathway. Within the mitochondrion, $\mathrm{HCO}_{3}^{-}$and calcium stimulate the production of $\mathrm{CAMP}$ by $\mathrm{SAC}_{\mathrm{t}}$, which activates mitochondrial CAMP production. In turn, CAMP stimulates oxidative phosphorylation and inhibits permeability transition via activation of mitochondrial Epac1 
another important player in cAMP signaling. ${ }^{20}$ Although Epac possesses a mitochondrial-targeting sequence at its $N$ terminus and has been shown to be localized inside mitochondria by heterologous expression, ${ }^{52}$ to our knowledge there has been no report on a role for this protein in mitochondrial function. Although the Epac2-selective inhibitor ESI05 had no effect, the non-selective inhibitor ESI09 or the Epac1-selective inhibitor CE3F4 antagonized the induction of MPT by $\mathrm{Ca}^{2+}$. This indicates that Epac1 but not Epac2 is involved in the regulation of MPT. We found also that CE3F4 inhibits oxygen consumption. As the efficiency of CE3F4 to regulate oxygen consumption with a better efficiency than MPT, we speculate that Epac1 could have several targets, which remain to be identified, regulating differentially various mitochondrial functions.

In neonatal rat cardiomyoctes, silencing of Epac1 modulated the $\mathrm{Ca}^{2+}$ entry and the $\Delta \Psi \mathrm{m}$. In the heart, Epac1 was recently shown to be localized and functionally involved also in nuclear signaling, whereas Epac2 is located at the T tubules and regulates arrhythmogenic sarcoplasmic reticulum $\mathrm{Ca}^{2+}$ leak. ${ }^{53}$ While the intermediate downstream effector(s) of mitochondrial Epac1 still need to be identified, our results indicate that Epac1 activation may inhibit MCU activity. This hypothesis is supported by the fact that inhibition of MCU, but not of $\mathrm{mNCX}$, mimics the effects of mitochondrial cAMP elevation in preventing MPT. Thus, we propose that activation of mitochondrial Epac1 protects the organelle from $\mathrm{Ca}^{2+}$ overload and from subsequent MPT via MCU modulation.

Possible implications of the mitochondrial cAMP pathway for cell death and cardioprotection. $\mathrm{Ca}^{2+}$ overload is considered as a conserved inducer of regulated cell death modalities. ${ }^{54}$ Using modulation of SAC by genetic and pharmacological manipulations in primary cardiomyocytes, our study demonstrates for the first time that activation of the mitochondrial cAMP pathway exerts an inhibition on MPT in vitro and on various cell death modalities, that is, extrinsic and intrinsic apoptosis as well as necrosis. Conversely, pharmacological inhibition of SAC increased markedly nuclear damage and cell death. Thus, the targeted activation of this mitochondrial cAMP pathway may preserve cardiomyocytes from mitochondrial $\mathrm{Ca}^{2+}$ overload and cell death in vivo. In that respect, in a pathological rat model of HF induced by pressure overload, which goes along with strong cardiac hypertrophy, cardiac function alteration, tissue remodeling, bioenergetic alterations and cardiomyocyte cell death, ${ }^{45,46} \mathrm{sACt}$ is downregulated and Epac1 is upregulated in mitochondria. However, the increase in Epac1 did not compensate the decrease of sACt in terms of function, suggesting that the level of cAMP is limiting for Epac1 in the control of MPT in cardiac mitochondria. Moreover, we found that the MPT alterations can be alleviated by stimulation of the mitochondrial CAMP pathway. Thus, this new mitochondrial $\mathrm{cAMP} / \mathrm{sAC} / \mathrm{Epac1/MCU}$ pathway might have therapeutic implications to regulate cell death in cardiac pathologies, such as HF and/or myocardial infarction. ${ }^{54,55}$

\section{Material and Methods \\ Unless specified, all reagents and chemicals are from Sigma-Aldrich (Saint-Quentin} Fallavier, France) and of analytical grade.
Animals. All animal care and experimental procedures conformed to the European Community guiding principles in the care and use of animals (Directive 2010/63/EU of the European Parliament) and authorizations to perform animal experiments according to this decree were obtained from the French Ministry of Agriculture, Fisheries and Food (No. D-92-283, 13 December 2012). All studies involving rats are reported in accordance with the ARRIVE guidelines for reporting experiments involving animals. ${ }^{56} \mathrm{~A}$ total of 60 healthy, 4 sham and $4 \mathrm{HF}$ rats were used in the experiments described here.

Surgical procedure and echocardiography. Male Wistar rats at 3 weeks of age (60-70 g; Janvier, Le Genest St Isle, France) were anesthetized with pentobarbital $(60 \mathrm{mg} / \mathrm{kg})$. The thoracic cage was opened and a stainless-steel hemoclip was placed on the ascending aorta, to promote HF after 22 weeks, as described previously. ${ }^{57}$ Sham-operated animals were used as controls. Cardiac structure and function was evaluated by echocardiograph. Cardiac and pulmonary hypertrophy was determined as a ratio of organ weight to tibia length and to body weight. ${ }^{57}$ Transthoracic two-dimensional-guided M-mode echocardiography of rats was performed using an echocardiograph with a $15 \mathrm{MHz}$ linear transducer (Vivid 9; General Electric Healthcare, Vélizy Villacoublay, France) under 3\% isoflurane gas anesthesia and fractional release was calculated as described. ${ }^{57}$

Isolation of cardiac mitochondria. Mitochondria were isolated from the heart of adult male Wistar rats at 8-10 weeks of age (275-375 g; Janvier) as described. ${ }^{37}$ Briefly, the heart was rapidly removed and placed into a cold buffer containing $0.3 \mathrm{M}$ sucrose, $0.2 \mathrm{mM}$ EGTA and $5 \mathrm{mM}$ TES (pH 7.2). The heart was grinded with Polytron fastly and homogenized by using the Potter. The homogenate was centrifuged at $500 \times \mathrm{g}$ for $10 \mathrm{~min}$ at $4^{\circ} \mathrm{C}$. Then, the supernatant was carefully removed and centrifuged again at $3000 \times g$ for $10 \mathrm{~min}$ at $4^{\circ} \mathrm{C}$. The pellets were washed in the isolation buffer and the mitochondria were kept on ice until use within $3 \mathrm{~h}$.

Mitochondrial transmembrane potential and swelling in isolated mitochondria. Isolated mitochondria ( $25 \mu$ g proteins) were incubated with $\mathrm{Ca}^{2+}$ and drugs in 96-well microtiter plates. ${ }^{37} \Delta \Psi \mathrm{m}$ was measured using the fluorescent probe, Rhod123 (excitation $=485 \mathrm{~nm}$ and emission $=535 \mathrm{~nm}$; Enzo Life Sciences, Villeurbanne, France) in a buffer containing $200 \mathrm{mM}$ sucrose, $10 \mathrm{mM}$ MOPS, $10 \mu \mathrm{M}$ EGTA, $1 \mathrm{mM} \mathrm{H}_{3} \mathrm{PO}_{4}, 5 \mathrm{mM}$ succinate and $2 \mu \mathrm{M}$ rotenone (pH 7.4) using Tecan Infinite 200 spectrofluorimeter (Tecan, Männedorf, Switzerland). In parallel, matrix swelling was measured via light absorbance at $540 \mathrm{~nm}^{37}$

Oxygen consumption. Isolated mitochondria (50 $\mu \mathrm{g}$ proteins) were incubated with drugs in a buffer containing $250 \mathrm{mM}$ sucrose, $30 \mathrm{mM} \mathrm{K}_{2} \mathrm{HPO}_{4}, 1 \mathrm{mM}$ EGTA, $5 \mathrm{mM} \mathrm{MgCl}_{2}, 15 \mathrm{mM} \mathrm{KCl}$ and $1 \mathrm{mg} / \mathrm{ml}$ bovine serum albumin (BSA) (pH 7.4) supplemented with respiratory substrates and MitoXpress, an oxygen-sensitive phosphorescent dye (LUXCEL, Cork, Ireland). Oxygen consumption was measured in real time for $60 \mathrm{~min}$ at $30^{\circ} \mathrm{C}$ in 96-well plates using Tecan Infinite 200 (excitation $=380 \mathrm{~nm}$ and emission $=650 \mathrm{~nm}$ ) in the presence of $1.65 \mathrm{mM} \mathrm{ADP}$ and with $5 \mathrm{mM}$ malate and $12.5 \mathrm{mM}$ glutamate. ${ }^{37}$

Mitochondrial $\mathrm{Ca}^{2+}$ uptake in isolated mitochondria. Isolated mitochondria (25 $\mu \mathrm{g}$ proteins) were incubated with $5 \mu \mathrm{M}$ Rhod-2 (Enzo Life Sciences) in the buffer containing $200 \mathrm{mM}$ sucrose, $10 \mathrm{mM}$ MOPS, $10 \mu \mathrm{M}$ EGTA, $1 \mathrm{mM} \mathrm{H} \mathrm{PO}_{4}, 5 \mathrm{mM}$ succinate and $2 \mu \mathrm{M}$ rotenone for $30 \mathrm{~min}$ in dark at room temperature. Afterwards, the mitochondria were washed two times. Then, the mitochondria were treated with various drugs for 10 min before applying $\mathrm{Ca}^{2+}$. Fluorescence was measured in real time for $60 \mathrm{~min}$ at room temperature in 96-well plates using Tecan Infinite 200 (excitation $=552 \mathrm{~nm}$ and emission $=581 \mathrm{~nm}$ ).

cAMP measurements by ELISA. CAMP measurements were performed according to the manufacturer's instructions using monoclonal anti-cAMP antibodybased direct cAMP ELISA Kit (New East Biosciences, King of Prussia, PA, USA) on freshly isolated mitochondria from rat hearts ( $500 \mu \mathrm{g}$ proteins per sample) treated or not by $\mathrm{HCO}_{3}^{-}, \mathrm{Ca}^{2+}$ and $\mathrm{Ca}^{2+}+\mathrm{Ru} 360$ for $20 \mathrm{~min}$ at room temperature before centrifugation and lysis. The sensitivity of cAMP detection is $29.6 \mathrm{fmol} / \mathrm{ml} .{ }^{57,58}$

ATP measurements. ATP measurements in isolated mitochondria were performed according to manufacturer's instructions using ATP Bioluminescence Assay Kit CLSII (Roche, Basel, Switzerland). 
Western blotting. Total mitochondrial proteins were resolved on 4-15\% Trisglycine SDS-PAGE gels and electroblotted onto polyvinylidene fluoride membranes (Bio-Rad, Marnes La Coquette, France). Following electrotransfer, membranes were blocked for $1 \mathrm{~h}$ at room temperature in $5 \%$ BSA-PBST (10 mM Tris- $\mathrm{HCl}$, pH 8.0/150 mM NaCl/0.1\% Tween-20). Next, membranes were incubated overnight at $4{ }^{\circ} \mathrm{C}$ with primary antibody. The day after, the membranes were washed six times with PBST and incubated with peroxidase-conjugated secondary antibody at room temperature for $1 \mathrm{~h}$. Peroxidase activity was detected with enhanced chemiluminescence (ECL Advance Western Blotting Detection Kit; Thermo Scientific, Villebon sur Yvette, France). For protein detection, the following antibodies were used: SAC (Abcam Cambridge, UK; CEP Biotech, Tamarac, FL, USA), Epac1, 2 (Cell Signaling, Danvers, MA, USA), ANT (Abcam), GAPDH (Cell Signaling), VDAC (Genosphere, Paris, France), Tnl (Cell Signaling), PLB (Cell Signaling) and MCU (Biorbyt, Berkeley, CA, USA).

Construction of mitochondria-targeted FRET sensor for cAMP. The mitochondrial-targeting sequence $4 \mathrm{mt}$, encoding four copies of the signal sequence from subunit VIII of human cytochrome $C$ oxidase, was amplified using the Advantage Polymerase (Clontech, Mountain View, CA, USA) and primers $\mathrm{F}, 5^{\prime}$ ACTATAGGGAGACCCAAGCTTATG-3' and R, 5'-TGGTGGCGGCAAGCTTCTTG CTCACCATGGTGGC-3'. The pcDNA-4mt-D3-cpv vector used as a matrix for amplification of $4 \mathrm{mt}$ was a kind gift from Dr. Roger Tsien (HHMI investigator at the University of California San Diego, San Diego, CA, USA). The PCR fragment was cloned into the Hindlll restriction site of pcDNA3-Epac- ${ }^{H 187}$ using the Infusion HD Cloning System (Clontech). Epac-S ${ }^{\mathrm{H} 187}$ encodes for a fourth-generation Epac1based cAMP sensor and was a kind gift from Dr. Kees Jalink (The Netherlands Cancer Institute, Amsterdam, Netherlands). ${ }^{36}$ Once the pcDNA-4mt-Epac-S ${ }^{\text {H187 }}$ vector was amplified in Stellar Escherichia coli (Clontech) bacteria, its identity with parental sequences was verified by PCR using primers $F, 5^{\prime}$-ACTCACTA TAGGGAGACC-3' and R, 5'-TGCGGCCGCCATGGTGGC-3', and DNA doublestrand sequencing (INSERM U1056 - UMR 5165 CNRS UPS - UDEAR, Toulouse, France). Adenoviruses encoding Epac-S ${ }^{\mathrm{H} 187}$ and $4 \mathrm{mt}-E$ pac-S $\mathrm{S}^{\mathrm{H} 187}$ were generated by Welgen Inc (Worcester, MA, USA).

Cardiomyocyte isolation, adenoviral infection and cell death evaluation. Adult and neonatal cardiomyocytes were isolated as described previously. ${ }^{59,60}$ For FRET experiments, neonatal cardiomyocytes were plated on $35-\mathrm{mm}$, laminin-coated culture dishes $(10 \mu \mathrm{g} / \mathrm{ml})$ at a density of $4 \times 10^{5}$ cells per dish. The day after, cells were infected with Epac-S ${ }^{\mathrm{H} 187}$ and $4 \mathrm{mt}-E$ Epac-S ${ }^{\mathrm{H} 187}$ adenoviruses in Opti-MEM (Life Technologies, St Aubin, France) for $48 \mathrm{~h}$. Similarly, adenoviruses expressing SACt and SACfl were used (generous gift from Pr. M Conti, University of California, San Francisco, CA, USA). For confocal microscopy experiments, adult cardiomyocytes were plated on $35-\mathrm{mm}$, laminin-coated culture dishes $(10 \mu \mathrm{g} / \mathrm{ml})$ at a density of $2 \times 10^{4}$ cells per dish. For cell death evaluation, neonatal cells were stained with Apoptosis/Necrosis Detection Kit (Abcam) for $1 \mathrm{~h}$ at room temperature as described by the manufacturer.

siRNA transfection to knockdown sAC and Epac1. On-Target plus SMART pool siRNA, a mixture of four siRNA provided as a single reagent were purchased from Dharmacon (Lafayette, CO, USA). At day 0 , neonatal cardiomyocytes were plated overnight on $35-\mathrm{mm}$, laminin-coated culture dishes $(10 \mu \mathrm{g} / \mathrm{ml})$ at $4 \times 10^{5}$. At day 1 , the cells were transfected with $50 \mathrm{nM} \mathrm{sAC/Epac1}$ or non-targeting control siRNA using Lipofectamine RNAi MAX Transfection Reagent (ThermoScientific, Waltham, MA, USA) for $48 \mathrm{~h}$.

Mitochondrial transmembrane potential measurement in neonatal cardiomyocytes. Isolated rat cardiomyocytes were loaded with $100 \mathrm{nM}$ TMRM at $37^{\circ} \mathrm{C}$ for $15 \mathrm{~min}$. Afterwards, the sarcolemmal membrane was permeabilized by perfusion of digitonin $(5 \mu \mathrm{g} / \mathrm{ml})$ in a $\mathrm{Ca}^{2+}$-free internal solution that contained $50 \mathrm{mM} \mathrm{KCl}, 80 \mathrm{mM}$ potassium aspartate, $4 \mathrm{mM}$ sodium pyruvate, $20 \mathrm{mM}$ HEPES, $3 \mathrm{mM} \mathrm{MgCl}$, $3 \mathrm{mM} \mathrm{Na} 2 \mathrm{ATP}, 5.8 \mathrm{mM}$ glucose and $0.5 \mathrm{mM}$ EGTA $(\mathrm{pH} 7.3$ with $\mathrm{KOH})$. Then, the free $\mathrm{Ca}^{2+}$ concentration in the internal solution was increased to $200 \mathrm{nM}$. The $\mathrm{Ca}^{2+}$ was calculated using the Maxchelator program from the Stanford University (Stanford, CA, USA). Images were acquired with a Leica (SP5) confocal microscope (Mannheim, Germany). Excitation was achieved by a white light laser fitted at $549 \mathrm{~nm}$ and emission collected at $570 \mathrm{~nm}$. Analyses were made with Image J program (Wayne Rasband, National Institutes of Health, USA).
Measurement of mitochondrial $\mathrm{Ca}^{2+}$ in cardiomyocytes. Isolated neonatal or adult rat cardiomyocytes were loaded with $5 \mu \mathrm{M}$ Rhod-2 at $37^{\circ} \mathrm{C}$ for $30 \mathrm{~min}$. To remove cytosolic Rhod-2, the sarcolemmal membrane was permeabilized by perfusion of digitonin $(5 \mu \mathrm{g} / \mathrm{ml})$ in a $\mathrm{Ca}^{2+}$-free internal solution that contained $50 \mathrm{mM} \mathrm{KCl}, 80 \mathrm{mM}$ potassium aspartate, $4 \mathrm{mM}$ sodium pyruvate, $20 \mathrm{mM}$ HEPES, $3 \mathrm{mM} \mathrm{MgCl}, 3 \mathrm{mM} \mathrm{Na} 2$ ATP, $5.8 \mathrm{mM}$ glucose and $0.5 \mathrm{mM}$ EGTA (pH 7.3 with $\mathrm{KOH})$. After the sarcolemmal membrane was permeabilized, the free $\mathrm{Ca}^{2+}$ concentration in the internal solution was increased to $200 \mathrm{nM}$. The $\mathrm{Ca}^{2+}$ was calculated using the Maxchelator program from Stanford University. Images were acquired with a Leica (SP5) confocal microscope. Excitation was achieved by a white light laser fitted at $552 \mathrm{~nm}$ and emission collected at $575 \mathrm{~nm}$. Analyses were made with Image J program.

FRET measurements of cAMP levels. FRET imaging experiments were performed $48 \mathrm{~h}$ after infection of neonatal cardiomyocytes. Cells were bathed in Hepes-buffered Ringer's solution containing: $125 \mathrm{mM} \mathrm{NaCl}, 25 \mathrm{mM} \mathrm{HEPES}, 10 \mathrm{mM}$ glucose, $5 \mathrm{mM} \mathrm{K}_{2} \mathrm{HPO}_{4}, 1 \mathrm{mM} \mathrm{MgSO}_{4}$ and $1 \mathrm{mM} \mathrm{CaCl}, \mathrm{pH}$ 7.4. For sAC activation by $\mathrm{HCO}_{3}^{-}$, the medium was the Krebs-Henseleit solution containing: $120 \mathrm{mM} \mathrm{NaCl}$, $2.09 \mathrm{mM} \mathrm{K}_{2} \mathrm{HPO}_{4}, 0.34 \mathrm{mM} \mathrm{KH}_{2} \mathrm{PO}_{4}, 24 \mathrm{mM} \mathrm{NaHCO}_{3}, 1 \mathrm{mM} \mathrm{MgSO}_{4}, 1 \mathrm{mM} \mathrm{CaCl}$ and $10 \mathrm{mM}$ D-glucose. Krebs-Henseleit solution was gassed continuously with $95 \%$ $\mathrm{O}_{2} / 5 \% \mathrm{CO}_{2}$ to maintain a $\mathrm{pH}$ of $7.4 .^{35}$ Real-time FRET experiments were performed at room temperature. Images were captured every $5 \mathrm{~s}$ using the $\times 40$ oil-immersion objective of an inverted microscope (Nikon, Champigny sur Marne, France) connected to a Cool SNAP HQ2 camera (Photometrics, Tucson, AZ, USA) controlled by the Metafluor software (Molecular Devices, Sunnyvale, CA, USA). The donor (mTurquoise2) ${ }^{36}$ was excited during $300 \mathrm{~ms}$ by a xenon lamp (Nikon) using a 440/20BP filter and a 455LP dichroic mirror. Dual-emission imaging of donor and acceptor was performed using a dual-view emission splitter equipped with a 510 LP dichroic mirror and BP filters $480 / 30$ and $535 / 25 \mathrm{~nm}$, respectively.

Data analysis. Results are expressed as mean \pm S.E.M. The Origin software (Northampton, MA, USA) was used for statistical analysis. Differences between groups have been analyzed by one-way ANOVA and Student's $t$-test. A value of $P<0.05$ were considered as statistically significant. The number of animals, cells and independent experiments performed is indicated in the figure legends.

\section{Conflict of Interest}

The authors declare no conflict of interest.

Acknowledgements. This work has been funded by INSERM (AMG, CB, GV $\mathrm{RF}$ ), the Investment for the Future program ANR-11-IDEX-0003-01 within the LABEX ANR-10-LABX-0033 (CB, GV, RF) and ANR (ANR-13-ISV1-0001-01, CB). ZW and $\mathrm{DL}$ are supported by a fellowship from the China Scholarship Council. The Leica microscope was funded by CORDDIM (Investissement 2010, COD100296). We thank Florence Lefebvre for her assistance in adult cardiomyocyte isolation and Valérie Domergue for animal housing and care at the Animex facility, IPSIT, ChâtenayMalabry, France. We also thank Christine Longin for Transmission Electron Microscopy at INRA, Jouy-en-Josas, France. We are also thankful to Jessica Sabourin, Cécile Martel, Delphine Mika and Jerôme Leroy for helpful discussions.

1. Green DR, Reed JC. Mitochondria and apoptosis. Science 1998; 281: 1309-1312.

2. Brenner $\mathrm{C}, \mathrm{Kroemer} \mathrm{G}$. Apoptosis. Mitochondria - the death signal integrators. Science 2000; 289: 1150-1151.

3. Desagher S, Martinou JC. Mitochondria as the central control point of apoptosis. Trends Cell Biol 2000; 10: 369-377.

4. Kroemer G, Galluzzi L, Brenner C. Mitochondrial membrane permeabilization in cell death. Physiol Rev 2007; 87: 99-163.

5. Duchen MR, Szabadkai G. Roles of mitochondria in human disease. Essays Biochem 2010; 47: 115-137.

6. Ichas F, Jouaville L, Mazat J. Mitochondria are excitable organelles capable of generating and conveying electrical and calcium signals. Cell 1997; 89: 1145-1153.

7. Rizzuto R, Pozzan T. Microdomains of intracellular $\mathrm{Ca}^{2+}$ : molecular determinants and functional consequences. Physiol Rev 2006; 86: 369-408.

8. Viola HM, Hool LC. Cross-talk between L-type Ca2+ channels and mitochondria. Clin Exp Pharmacol Physiol 2010; 37: 229-235.

9. Luongo TS, Lambert JP, Yuan A, Zhang X, Gross P, Song J et al. The mitochondrial calcium uniporter matches energetic supply with cardiac workload during stress and modulates permeability transition. Cell Rep 2015; 12: 23-34. 
10. Kwong JQ, Lu X, Correll RN, Schwanekamp JA, Vagnozzi RJ, Sargent MA et al. The mitochondrial calcium uniporter selectively matches metabolic output to acute contractile stress in the heart. Cell Rep 2015; 12: 15-22.

11. Griffiths EJ, Halestrap AP. Mitochondrial non-specific pores remain closed during cardiac ischaemia, but open upon reperfusion. Biochem J 1995; 307(Part 1): 93-98.

12. Halestrap AP, Richardson AP. The mitochondrial permeability transition: a current perspective on its identity and role in ischaemia/reperfusion injury. J Mol Cell Cardiol 2015; 78C: $129-141$

13. Boerma M. Experimental radiation-induced heart disease: past, present, and future. Radiat Res 2012; 178: 1-6.

14. Kwong JQ, Molkentin JD. Physiological and pathological roles of the mitochondrial permeability transition pore in the heart. Cell Metab 2015; 21: 206-214.

15. Piot $C$, Croisille $P$, Staat $P$, Thibault $H$, Rioufol $G$, Mewton $N$ et al. Effect of cyclosporine on reperfusion injury in acute myocardial infarction. N Engl J Med 2008; 359: 473-481.

16. Guellich A, Mehel H, Fischmeister R. Cyclic AMP synthesis and hydrolysis in the normal and failing heart. Pflugers Archiv 2014; 466: 1163-1175.

17. de Rooij J, Zwartkruis FJ, Verheijen MH, Cool RH, Nijman SM, Wittinghofer A et al. Epac is a Rap1 guanine-nucleotide-exchange factor directly activated by cyclic AMP. Nature 1998; 396: 474-477.

18. Kawasaki H, Springett GM, Toki S, Canales JJ, Harlan P, Blumenstiel JP et al. A Rap guanine nucleotide exchange factor enriched highly in the basal ganglia. Proc Natl Acad SCi USA 1998; 95: 13278-13283.

19. Schmidt M, Dekker FJ, Maarsingh H. Exchange protein directly activated by cAMP (epac): a multidomain CAMP mediator in the regulation of diverse biological functions. Pharmacol Rev 2013; 65: 670-709.

20. Metrich M, Berthouze M, Morel E, Crozatier B, Gomez AM, Lezoualc'h F. Role of the cAMP. binding protein Epac in cardiovascular physiology and pathophysiology. Pflugers Archiv 2010; 459: 535-546.

21. Chen H, Wild C, Zhou X, Ye N, Cheng X, Zhou J. Recent advances in the discovery of small molecules targeting exchange proteins directly activated by CAMP (EPAC). J Med Chem 2014; 57: 3651-3665

22. Parnell E, Palmer TM, Yarwood SJ. The future of EPAC-targeted therapies: agonism versus antagonism. Trends Pharmacol Sci 2015; 36: 203-214.

23. Litvin TN, Kamenetsky M, Zarifyan A, Buck J, Levin LR. Kinetic properties of 'soluble' adenylyl cyclase. Synergism between calcium and bicarbonate. J Biol Chem 2003; 278 15922-15926.

24. Jaiswal BS, Conti M. Calcium regulation of the soluble adenylyl cyclase expressed in mammalian spermatozoa. Proc Natl Acad Sci USA 2003; 100: 10676-10681.

25. Spät A, Katona D, Rajki A, Di Benedetto G, Pozzan T. Calcium-dependent mitochondrial cAMP production enhances aldosterone secretion. Mol Cell Endocrinol 2015; 412 196-204.

26. Kamenetsky M, Middelhaufe S, Bank EM, Levin LR, Buck J, Steegborn C. Molecular details of cAMP generation in mammalian cells: a tale of two systems. J Mol Biol 2006; 362: 623-639.

27. Acin-Perez R, Salazar E, Kamenetsky M, Buck J, Levin LR, Manfredi G. Cyclic AMP produced inside mitochondria regulates oxidative phosphorylation. Cell Metab 2009; 9: 265-276.

28. Zippin JH, Levin LR, Buck J. $\mathrm{CO}(2) / \mathrm{HCO}(3)(-)$-responsive soluble adenylyl cyclase as a putative metabolic sensor. Trends Endocrinol Metab 2001; 12: 366-370.

29. Di Benedetto G, Scalzotto E, Mongillo M, Pozzan T. Mitochondrial $\mathrm{Ca}(2+)$ uptake induces cyclic AMP generation in the matrix and modulates organelle ATP levels. Cell Metab 2013; 17: $965-975$.

30. Acin-Perez R, Russwurm M, Gunnewig K, Gertz M, Zoidl G, Ramos L et al. A phosphodiesterase $2 \mathrm{~A}$ isoform localized to mitochondria regulates respiration. $\mathrm{J} \mathrm{Biol}$ Chem 2011; 286: 30423-30432.

31. Kumar S, Flacke JP, Kostin S, Appukuttan A, Reusch HP, Ladilov Y. SLC4A7 sodium bicarbonate co-transporter controls mitochondrial apoptosis in ischaemic coronary endothelial cells. Cardiovasc Res 2011; 89: 392-400.

32. Kumar S, Kostin S, Flacke JP, Reusch HP, Ladilov Y. Soluble adenylyl cyclase controls mitochondria-dependent apoptosis in coronary endothelial cells. J Biol Chem 2009; 284: 14760-14768.

33. Acin-Perez R, Salazar E, Brosel S, Yang H, Schon EA, Manfredi G. Modulation of mitochondrial protein phosphorylation by soluble adenylyl cyclase ameliorates cytochrome oxidase defects. EMBO Mol Med 2009; 1: 392-406.

34. Neubauer S. The failing heart - an engine out of fuel. N Engl J Med 2007; 356: 1140-1151.

35. Lefkimmiatis K, Leronni D, Hofer AM. The inner and outer compartments of mitochondria are sites of distinct cAMP/PKA signaling dynamics. J Cell Biol 2013; 202: 453-462.

36. Klarenbeek J, Goedhart J, van Batenburg A, Groenewald D, Jalink K. Fourth-generation epac-based FRET sensors for CAMP feature exceptional brightness, photostability and dynamic range: characterization of dedicated sensors for FLIM, for ratiometry and with high affinity. PLoS One 2015; 10: e0122513.

37. Wang Z, Nicolas C, Fischmeister R, Brenner C. Enzymatic assays for probing mitochondria apoptosis. Methods Mol Biol 2015; 1265: 407-414.

38. Buck J, Sinclair ML, Schapal L, Cann MJ, Levin LR. Cytosolic adenylyl cyclase defines a unique signaling molecule in mammals. Proc Natl Acad Sci USA 1999; 96: 79-84.
39. Brenner C, Moulin M. Physiological roles of the permeability transition pore. Circ Res 2012; 111: $1237-1247$.

40. Belzacq-Casagrande AS, Martel C, Pertuiset C, Borgne-Sanchez A, Jacotot E, Brenner C. Pharmacological screening and enzymatic assays for apoptosis. Front Biosci 2009; 14: 3550-3562.

41. Sardanelli AM, Technikova-Dobrova Z, Scacco SC, Speranza F, Papa S. Characterization of proteins phosphorylated by the CAMP-dependent protein kinase of bovine heart mitochondria. FEBS Lett 1995; 377: 470-474.

42. Carlucci A, Lignitto L, Feliciello A. Control of mitochondria dynamics and oxidative metabolism by CAMP, AKAPs and the proteasome. Trends Cell Biol 2008; 18: 604-613.

43. Chen H, Ding C, Wild C, Liu H, Wang T, White MA et al. Efficient synthesis of ESI-09, a novel non-cyclic nucleotide EPAC antagonist. Tetrahedron Lett 2013; 54: 1546-1549.

44. Courilleau D, Bouyssou P, Fischmeister R, Lezoualc'h F, Blondeau JP. The (R)-enantiomer of CE3F4 is a preferential inhibitor of human exchange protein directly activated by cyclic AMP isoform 1 (Epac1). Biochem Biophys Res Commun 2013; 440: 443-448.

45. Joubert F, Wilding JR, Fortin D, Domergue-Dupont V, Novotova M, Ventura-Clapier R et al. Local energetic regulation of sarcoplasmic and myosin ATPase is differently impaired in rats with heart failure. J Physiol 2008; 586(Part 21): 5181-5192.

46. Marcil M, Ascah A, Matas J, Bélanger S, Deschepper C, Burelle Y. Compensated volume overload increases the vulnerability of heart mitochondria without affecting their functions in the absence of stress. J Mol Cell Cardiol 2006; 41: 998-1009.

47. Zippin JH, Chen $Y$, Nahirney $P$, Kamenetsky M, Wuttke MS, Fischman DA et al. Compartmentalization of bicarbonate-sensitive adenylyl cyclase in distinct signaling microdomains. FASEB J 2003; 17: 82-84.

48. Sulimovici S, Lunenfeld B. Effect of gonadotrophins on adenylate cyclase of the outer and inner membrane subfractions of rat testis mitochondria. FEBS Lett 1974; 41: 345-347.

49. Fine AS, Egnor RW, Forrester E, Stahl SS. Adenylate cyclase localization in unfixed specimens of rat oral mucosa and isolated mitochondria. J Histochem Cytochem 1982; 30: $1171-1178$.

50. Papa S, De Rasmo D, Scacco S, Signorile A, Technikova-Dobrova Z, Palmisano G et al. Mammalian complex I: a regulable and vulnerable pacemaker in mitochondrial respiratory function. Biochim Biophys Acta 2008; 1777: 719-728.

51. Acin-Perez R, Gatti DL, Bai Y, Manfredi G. Protein phosphorylation and prevention of cytochrome oxidase inhibition by ATP: coupled mechanisms of energy metabolism regulation. Cell Metab 2011; 13: 712-719.

52. Qiao J, Mei FC, Popov VL, Vergara LA, Cheng X. Cell cycle-dependent subcellular localization of exchange factor directly activated by cAMP. J Biol Chem 2002; 277 : 26581-26586.

53. Pereira L, Rehmann H, Lao DH, Erickson JR, Bossuyt J, Chen J et al. Novel Epac fluorescent ligand reveals distinct Epac1 vs. Epac2 distribution and function in cardiomyocytes. Proc Natl Acad Sci USA 2015; 112: 3991-3996.

54. Galluzzi L, Bravo-San Pedro JM, Vitale I, Aaronson SA, Abrams JM, Adam D et al. Essential versus accessory aspects of cell death: recommendations of the NCCD 2015. Cell Death Differ 2015; 22: 58-73.

55. Kung G, Konstantinidis K, Kitsis RN. Programmed necrosis, not apoptosis, in the heart. Circ Res 2011; 108: 1017-1036.

56. Kilkenny C, Browne W, Cuthill IC, Emerson M, Altman DG. Animal research: reporting in vivo experiments: the ARRIVE guidelines. Br J Pharmacol 2010; 160: 1577-1579.

57. Hubert F, Belacel-Ouari M, Manoury B, Zhai K, Domergue-Dupont V, Mateo P et al. Alteration of vascular reactivity in heart failure: role of phosphodiesterases 3 and $4 . \mathrm{Br} \mathrm{J}$ Pharmacol 2014; 171: 5361-5375.

58. Chen Y, Cann MJ, Litvin TN, lourgenko V, Sinclair ML, Levin LR et al. Soluble adenylyl cyclase as an evolutionarily conserved bicarbonate sensor. Science 2000; 289: 625-628.

59. Morel E, Marcantoni A, Gastineau M, Birkedal R, Rochais F, Garnier A et al. cAMP-binding protein Epac induces cardiomyocyte hypertrophy. Circ Res 2005; 97: 1296-1304.

60. Rochais F, Vandecasteele G, Lefebvre F, Lugnier C, Lum H, Mazet J et al. Negative feedback exerted by CAMP-dependent protein kinase and CAMP phosphodiesterase on subsarcolemmal CAMP signals in intact cardiac myocytes: an in vivo study using adenovirusmediated expression of CNG channels. J Biol Chem 2004; 279: 52095-52105.

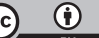

Cell Death and Disease is an open-access journal published by Nature Publishing Group. This work is licensed under a Creative Commons Attribution 4.0 International License. The images or other third party material in this article are included in the article's Creative Commons license, unless indicated otherwise in the credit line; if the material is not included under the Creative Commons license, users will need to obtain permission from the license holder to reproduce the material. To view a copy of this license, visit http://creativecommons.org/licenses/by/4.0/ 